\title{
New Delivery Systems of Stem Cells for Vascular Regeneration in Ischemia
}

\author{
Adegbenro Omotuyi John Fakoya* \\ Department of Anatomical Sciences, All Saints University School of Medicine, Roseau, Dominica
}

The finances of patients and countries are increasingly overwhelmed with the plague of cardiovascular diseases as a result of having to chronically manage the associated complications of ischemia such as heart failures, neurological deficits, chronic limb ulcers, gangrenes, and amputations. Hence, scientific research has sought for alternate therapies since pharmacological and surgical treatments have fallen below expectations in providing the desired quality of life. The advent of stem cells research has raised expectations with respect to vascular regeneration and tissue remodeling, hence assuring the patients of the possibility of an improved quality of life. However, these supposed encouraging results have been short-lived as the retention, survival, and engraftment

OPEN ACCESS

Edited by:

Andrea Caporali,

University of Edinburgh, UK

Reviewed by:

Rajesh Katare,

University of Otago, New Zealand Mauro Siragusa,

Goethe University Frankfurt, Germany

${ }^{*}$ Correspondence: Adegbenro Omotuyi John Fakoya gbenrofakoya@gmail.com

Specialty section: This article was submitted to Cardiovascular Biologics and

Regenerative Medicine,

a section of the journal

Frontiers in Cardiovascular Medicine

Received: 03 December 2016 Accepted: 07 February 2017

Published: 24 February 2017

Citation:

Fakoya AOJ (2017) New Delivery

Systems of

Stem Cells for Vascular

Regeneration in Ischemia.

Front. Cardiovasc. Med. 4:7. doi: 10.3389/fcvm.2017.00007 rates of these cells appear to be inadequate; hence, the long-term beneficial effects of these cells cannot be ascertained. These drawbacks have led to the relentless research into better ways to deliver stem cells or angiogenic factors (which mobilize stem cells) to the regions of interest to facilitate increased retention, survival, engraftment, and regeneration. This review considered methods, such as the use of scaffolds, retrograde coronary delivery, improved combinations, stem cell pretreatment, preconditioning, stem cell exosomes, mannitol, magnet, and ultrasound-enhanced delivery, homing techniques, and stem cell modulation. Furthermore, the study appraised the possibility of a combination therapy of stem cells and macrophages, considering the enormous role macrophages play in repair, remodeling, and angiogenesis.

Keywords: ischemia, stem cells, delivery, growth factors, angiogenesis, transplantation, macrophages

\section{INTRODUCTION}

Ischemia is a partial or complete interruption of blood supply to a tissue or organ with an accompanying interruption of the flow of oxygen, glucose, and tissue washout resulting in tissue death by necrosis. Most pertinent to the medical practice are cardiovascular diseases (CVDs), a disease of the heart and blood vessels of which myocardial infarction (MI), stroke, and peripheral arterial diseases (PAD) is the most notable. More than 27 million Americans (1) and 202 million people worldwide (2) have experienced an ischemic heart event, stroke, or hospitalization for heart failure, peripheral arterial disease with smoking, increasing age, and diabetes being major risk factors (2). The American Heart Association estimates the annual cost of CVD to be $\$ 155$ billion in direct health-care costs and another $\$ 92$ billion in indirect costs reflecting lost productivity (3). CVDs, mainly acute MI, caused by the occlusion of the coronary arteries are the leading cause of mortality worldwide $(4,5)$. CVD usually damages the heart 
muscle cells [cardiomyocytes (CMCs)] irreversibly resulting in complications associated with MI such as early mortality occurring from arrhythmias such as ventricular tachycardias and fibrillations $(6,7)$. CMCs have previously been regarded as post-mitotic cells; however, increasing research evidence has disproved this with observations revealing that ischemic events may influence the proliferative capacity of adult mammalian CMCs (8), though young adult CMCs have an annual renewal rate of about 1\% (9). The world heart federation, 2016, stated that stroke which occurs as a result of the loss of blood supply to the brain is the seconding leading cause of mortality over 60 years of age and the fifth between the ages of 15 and 59 years resulting in a long-term neurological deficit. Another debilitating ischemia is that of the lower limb, which may lead to gangrene and ultimately amputation of the affected limb. Lower limb ischemia can either be an acute (as a result of an arterial embolism) or a critical limb ischemia (which is an end-stage result of a PAD) affecting about 2 million Americans $(1,10)$. Atherosclerosis, an inflammatory disease, is the primary pathophysiology underlying CVDs in which endothelial dysfunction is a critical initial event in its pathogenesis, and this contributes to the initiation and progression of plaque (11, 12). Research has been carried out on diverse stem cells with rather promising results. However, quite a few challenges still need to be overcome, such as identifying the most appropriate mode of delivery, timing of delivery, survival, retention, and integration of these therapeutic cells to the site of ischemia with enhancement of revascularization and angiogenesis. The goal of a delivery system is to be able to transplant the right amount of (stem) cells to the site of interest and attain the maximal cell retention and ultimately prevent the deleterious effect of the ischemia such as amputation, heart failure, and neurological deficits. Thus, this study examined previous methods of stem cell delivery and the new methods being used to deliver stem cells for an efficient vascular regeneration.

\section{METHODS}

Data for this study were obtained from Medline on OvidSP, which includes PubMed, Embase by the US National Library of Medicine as well as a search through the University of Bristol Library services.

\section{Search Strategy}

The search was carried out by signing into Ovid, Wolters, and Kluver portal and "All Resources" was selected. The keyword "stem cell delivery" was used with a further selection made on stem cell transplantation. So search for stem cell delivery/stem cell transplantation gave a total number of 19,919 publications. The second search with the keyword "ischemia/tissue ischemia" yielded a total number of 46,597 articles.

Combining the search for "stem cell delivery/stem cell transplantation" using the Boolean operator "AND” with "ischemia/ tissue ischemia" yielded a total of 274 publications. Publications were then further hand screened to ascertain if they fit into the inclusion the criteria for the study and I arrived at a total of about 66 .
However, other data included in the release were obtained from the University library services by simply using the search phrase "stem cell delivery" and "stem cells in ischemia" and articles around vasculogenesis/angiogenesis and were hand screened to fit the inclusion criteria and 38 other publications were selected. Also included were relevant references from previously selected articles as well as some recommended publications. A total of 171 articles were reviewed.

\section{Inclusion Criteria}

Publications selected were analyzed thoroughly to see if they focused on the study which was on delivery of stem cells in the setting of ischemia. Included were studies that utilized stem cells (such as embryonic, mesenchymal, adult, endothelial progenitor, cardiac, hematopoietic, and induced pluripotent stem cells) in the setting of ischemia such as myocardial ischemia, limb ischemia, and cerebral ischemia. Also considered were publications which included scaffolds in the delivery of stem cells and new modes of targeting and delivering stem cells to sites of ischemia and articles that also considered tracking of these cells to target sites.

\section{BRIEF OVERVIEW OF THE MOLECULAR BASIS OF BLOOD VESSEL FORMATION}

Vasculogenesis and angiogenesis are the two methods for blood vessel formation. The formation of primordial blood vessels is known as vasculogenesis, and this occurs during embryogenesis as a result of increasing metabolic and oxygen demands of the organs of the embryo as their sizes increases. Four major steps are involved in this, and this includes (i) mesoderm formation, (ii) differentiation into blood islands, (iii) blood island fusion, and (iv) primary capillary plexus formation. Nevertheless, new sites of vascularizations have been demonstrated in adults as well (13). Angiogenesis, however, is the formation of new blood vessels from previously existing ones, and two processes are involved in this (i) budding/sprouting, this is the growth phase, where stabilization of new blood vessels occurs and (ii) intussusception, here the local vascular network is remodeled by the insertion of interstitial cells which helps to partition the new vessels (14).

Vasculogenesis is initiated in the embryo by the fibroblast growth factor (FGF) ligand/receptor system inducing the mesoderm to form blood islands. The endoderm then releases the vascular endothelial growth factor (VEGF) following the expression of its receptors VEGF-R2 (Flk-1) and SCL/ TAL- 1 by haemangioblasts thus facilitating its differentiation into hematopoietic and endothelial cell (EC) lines. Another receptor, VEGF-R1 (Flt-1) is also released but however utilized late in angiogenesis to promote aggregation of angioblasts. VEGF facilitates differentiation into ECs, while platelet-derived growth factor (PDGF)-BB induces smooth muscle (SMC) formation and is mitogen and for both SMCs and pericytes. Angiopoietin (Ang-1), a Tie-1(tek) ligand enhances luminal formation and stabilization, while Ang-2 halts the process. EC proliferation is then enhanced by PDGF-BB bound to 
receptor PDGFBR and transforming growth factor (TGF)-B1 antagonizes this by facilitating the contact between ECs and pericytes (14). Other factors involved in adhesion of ECs and junction formation include endothelial transcriptase (ets)-1, platelet endothelial cell adhesion molecule (PECAM)-1 (CD31), vascular endothelial-cadherin, and CD34 (15). Figure 1 below shows the schematic representation of the process of vasculogenes.

Angiogenesis on the hand involves (i) migration of ECs, (ii) tubulogenesis, (iii) vessel maturation, and (iv) vessel stabilization. The expression of either VEGF or hepatocyte growth factor (HGF), which initiates angiogenesis facilitates this process by subtly different mechanisms.
Vascular endothelial growth factor, when expressed, increases the permeability of vessels causing the release of fibrinogen which triggers coagulation. Coagulation and fibrinolysis are regulated by tissue plasminogen activator (tPA) and urokinase-type plasminogen activator ( $\mathrm{UPA}$ ), respectively, with plasminogen activator inhibitor-1 inhibiting both and favoring the EC detachment from the matrix (16). Clots are dissolved by plasmin which also activates metalloproteinases (MMP), the binding of MMPs to the protein Vitronectin (facilitates binding to $\alpha v \beta 3$ ) stabilizes it. The secreted MMPs encourage the breakdown of the basal lamina by the EC and then its matrix. While collagen type 1 is being degraded by the MMPs, the RGD (Arginine-Glycine-Aspartate) sequences are exposed enhancing its binding to $\alpha v \beta 3$ integrin.

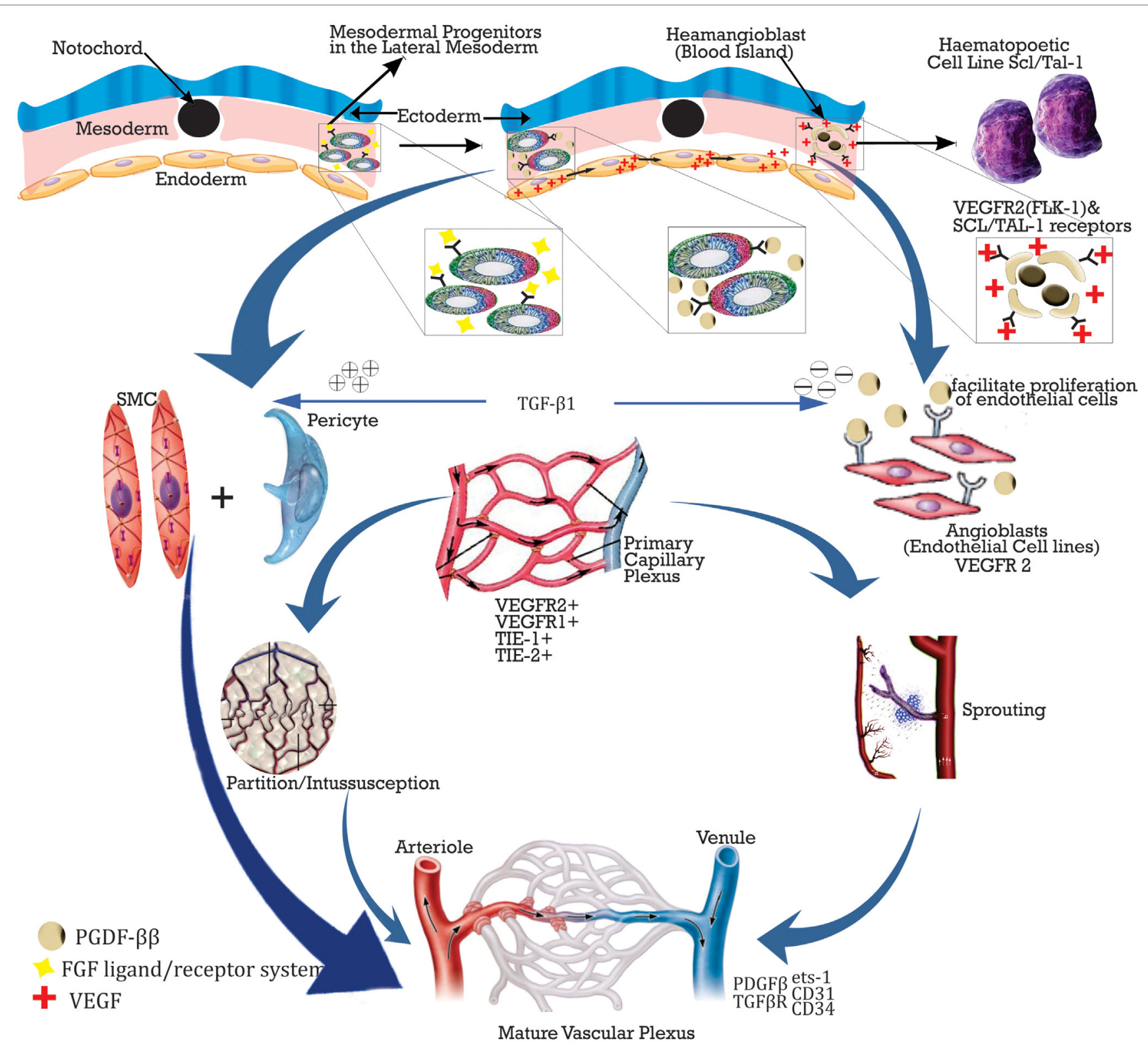

FIGURE 1 | Summary of vasculogenesis and angiogenesis with some molecular overview. 
The formation of a new basal lamina which blocks the contact between the EC and collagen type 1 stops the progression. bFGF and VEGF/protein kinase $\mathrm{C}$ induce the integrins $\alpha v \beta 3$ and $\alpha v \beta 5$, respectively (16).

After the formation of these vessels, there is the need to determine their arterial-venous identity. Notch ligand and receptors are regulators of cell fate, while regulators of arterial fate include VEGF and Ephrin B2 with Ephrin B4 and Coup-TFII being venous cell fate regulators (17).

Overall, a couple of factors help to halt the angiogenic process, and these include tissue inhibitors of MMPs (TIMP), cytokines such as IL-4, IL-10, IL-12, thrombospondins-1 and 2, MMP2 c-terminal lytic fragments. Other angiostatic agents include endostatin, angiostatin, maspin, and TGF $\beta$ (16). See Figure 2.

Hepatocyte growth factor considered the angiogenic factor with the most potency affects both the ECs and SMCs. The binding of HGF to its C-met receptor activates Ets-1, which then facilitates the expression of the factors necessary for angiogenesis and regeneration (18). Figure 3 below summarizes the event.

However, during ischemic/hypoxic states, the expression of hypoxia-inducible factor (HIF)-1 is induced. HIF is a transcription factor which encodes for the angiogenic cytokines. It has two subunits: the alpha is regulated by oxygen while the beta is constitutively expressed (21). These angiogenic cytokines with their respective receptors include VEGF/VEGFR1, placental growth factor/VEGFR2, stromal-derived factor (SDF)-1/ chemokine receptor 4 (CXCR4) (22). In muscle ischemia, for instance, there is an elaboration of a higher than normal SDF-1, which facilitates the mobilization of hematopoietic stem cells (HSCs) from the bone marrow niche to the peripheral circulation. The stem cells are recruited to the site of ischemia where the ligands SDF-1, stem cell factor, and fibronectin are bound by their respective receptors CXCR $4, \mathrm{C}-\mathrm{Kit}$, and $\alpha-4$ integrin on the stem cells.

In tissue hypoxia, the elaborate intracellular oxygen sensor proteins, the protein hydroxylase domain-containing proteins 1-3, and the HIF-1 and 2 analyze cellular oxygen content and induce a response to counteract the deficient oxygen supply (23). The abundance of HIF is not solely controlled by PHDs but also by nitric oxide (NO) even in normoxic conditions. NO influences the accumulation of HIF-1a protein by preventing its degradation independent of gene transcription and translation (24). VEGF is induced in an HIF-1a dependent manner during EC hypoxia and HIF-1a and 2a cannot be substituted for one another as they perform distinct roles in angiogenesis (23).

Nitric oxide, similar to VEGF, is a potent angiogenic and vascular permeability factor which plays a vital function in both physiological and pathological angiogenesis (25). Three isoforms of NO synthase exists, which are neuronal NOS, inducible NOS (iNOS), and endothelial NOS (eNOS). VEGF enhances NO synthesis and likewise induces the expression of iNOS and eNOS (expressed constitutively in vascular endothelial cells) (23). Thus the assumption that vascular EC eNOS synthesizes $\mathrm{NO}$ in response to VEGF, and this NO mediates the increased

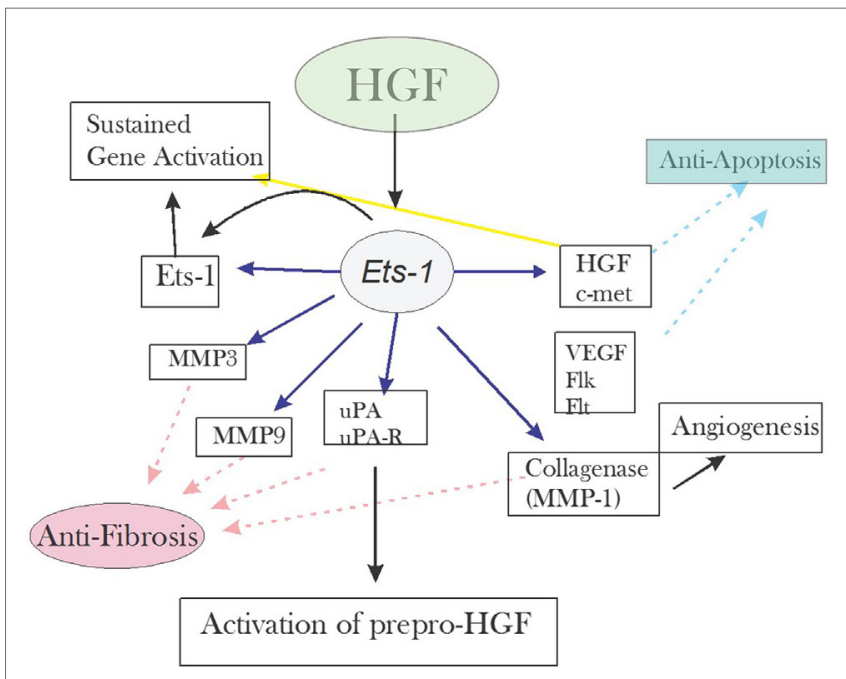

FIGURE 3 | Redrawn from Ref. $(19,20)$

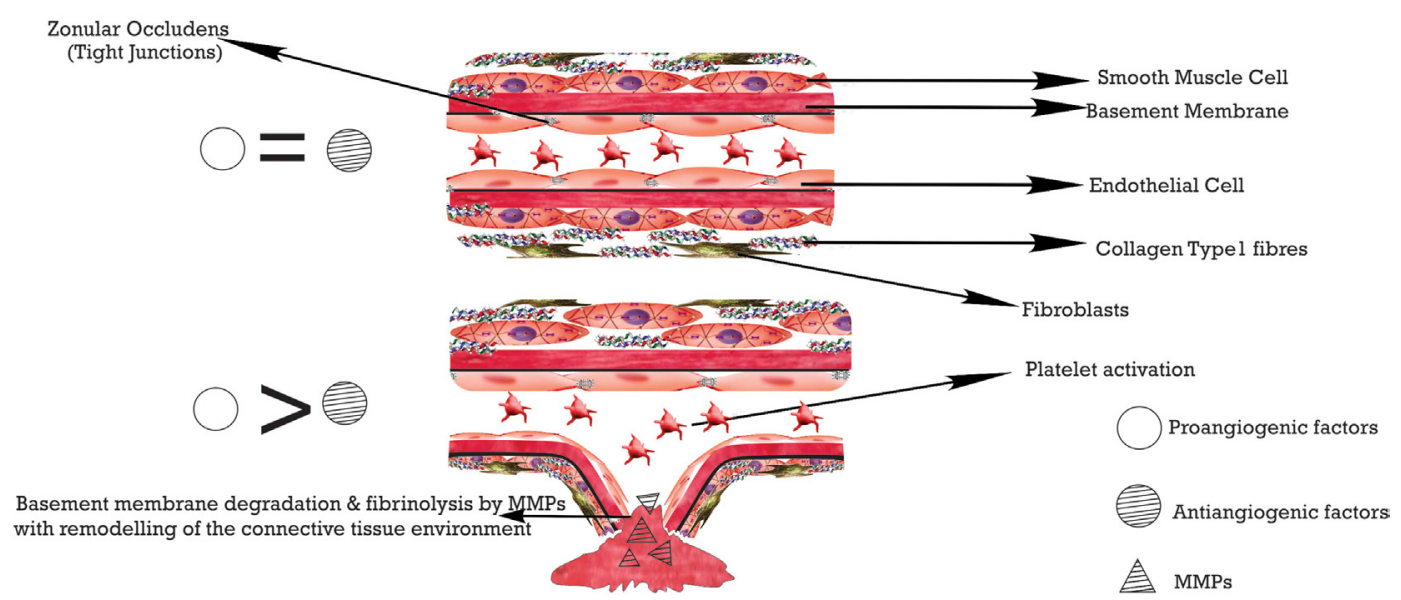

FIGURE 2 | ECM modification with the degradation of the basement membrane during angiogenesis 
vascular permeability and angiogenesis induced by VEGF. NO synthesized by iNOS also mediates both vascular permeability and angiogenesis, however to a lesser degree than eNOS (23). The $\mathrm{NO}$ enhanced angiogenesis may be more of pathological such as in solid tumors than the physiological angiogenesis which occurs in development and vasculogenesis.

Other angiogenesis enhancing factors (mobilizers) include erythropoietin, granulocyte colony stimulating factor, statins, estrogen, exercise, and peroxisome proliferator-activated receptor $(\operatorname{PPAR} \gamma)$, and these utilize ECs or endothelial progenitor cells (EPC) from circulation, bone marrow, or exogenously administered.

This molecular background drives the diverse studies and therapeutic approaches used in the field of stem cells and regeneration, and this knowledge is fundamental and is key to the understanding of this review.

\section{STEM CELLS IN ISCHEMIA}

Several treatment lines are available for patients with CVDs especially those who might have suffered an MI. These ranges from aspirin to nitroglycerin, B-blockers, and anticoagulants. However, those with occlusive symptoms are subjects for immediate reperfusion therapies with thrombolytics/percutaneous coronary intervention, commonly called coronary angioplasty. Coronary bypass graft surgery (CABG) is usually done when all reperfusion therapies have failed. Though these procedures undeniably have saved a lot of lives, the quality of life somewhat is still not optimal, especially in the case of an MI with a resulting permanent damage (Scar). On the other hand, for limb ischemias, drug-eluting stents/ drug-coated balloons in femoral and popliteal arterial segments, others include adventitial anti-inflammatory therapy, stimulation of the spinal cord, and intermittent air(pneumatic) compression.

Also, several clinical trials using angiogenic factors like VEGF, FGF, HGF have bene tried on patients with not so encouraging results (26). Thus, the enormous clinical burden posed by CVDs have immensely stimulated directions toward gene and cellular therapies (27). Stem cells or progenitor cells have been proven to have the potentials to differentiate into any tissue type in the body including the cardiovascular system (such as endothelial cells, smooth muscles, and CMCs). With this potential, we see stem cells not just being able to repair or regenerate tissues but also facilitate revascularization.

\section{Stem Cells Utilized in Ischemic Models}

Several studies have been carried out in animals using diverse populations of (stem) cells for the treatment of CVDs and hind limb ischemias. These includes embryonic stem cells (ESC) $(28,29)$, mesenchymal stem cells (MSC) $(30,31)$, bone marrow mononuclear cells (BMMNC) $(32,33)$, endothelial progenitor cells (EPC) $(34,35)$, mature ECs (34), marrow-derived stromal cells (36), peritoneal macrophages (37), polarized macrophages (38), adipose tissue-derived stem cells (39), autologous cultured adipose-derived stem cells (40), saphenous vein progenitors (SVPs) (41), pericytes (42).

Despite the benefits of these stem cells, tumor formation and immune intolerance have been a major drawback to their use.
Among others, MSCs are considered one of the main and the most attractive sources for stem cell therapy for reasons such as low tumorigenic potentials $(43,44)$, ease of access as well as minimal immunogenicity (45). Also, ESCs are quite immune privileged but they may trigger some inflammation via their derivatives (46).

Overall, most researchers believe that the benefits derived from stem cells do not occur through the transdifferentiation of stem cells but rather from their paracrine functions which include the release of cytokines and growth factors (47-49).

\section{STEM CELLS DELIVERY, RESULTS, AND DISCUSSION}

Stem cells have been transplanted or administered in the setting of ischemia through various routes. In the case of an MI from the clinical point of view, these have been through routes such as (i) transvenous infusion, (ii) intracoronary arterial infusion, (iii) direct intramyocardial injection with CABG, (iv) trans-endocardial injection using catheter, and (v) mobilization of stem cells. Zhou and colleagues documented the routes for the administration of stem cells in critical limb ischemia, these are the intra-arterial, intramuscular, or the combination of both. For an MI, the two most utilized methods are CABG with intramyocardial injection and the intracoronary infusion, while the intramuscular injection is the most preferred method during limb ischemia (50).

The transvenous route, though an easy approach for stem cell delivery in myocardial injury, relies majorly on a successful homing process and stem cell retention (51).

The intracoronary route of delivery encourages the homogenous administration of a maximum number of cells to the damaged site. However, the non-perfused areas do not benefit (52).

Direct intramyocardial injection is the most preferred method of delivery, particularly for patients with chronic heart failure (53). However, necrosed tissues are oxygen and nutrient deprived, and injected cells would not have healthy cardiac cells to provide paracrine support, hence a reduction in differentiation and graft survival (50).

The Table 1 below shows the advantages and limitations of the methods of delivery stem cells.

Researchers have investigated best possible methods for stem cells delivery which will result in a successful neovascularization. The goal is ensuring a successful homing of the cells to regions of ischemia, prolonging survival, and retention of these cells, as less than $10 \%$ of cells are retained after $24 \mathrm{~h}$ and only about $1 \%$ after 4 weeks (54). Furthermore, methods that non-invasive are being considered because of the hazards associated with operative procedures. Taking stroke as a case study, injecting neural stem cells or mesenchymal cells directly into the lesioned brain might yield a remarkable result, but the use of a non-invasive technique could be used to avoid the associated operative hazards.

The new methods which have been used for the delivery of stem cells include

(a) Scaffolds

(b) Retrograde delivery 
TABLE 1 | Advantages and limitations of routes of delivery.

\begin{tabular}{lll}
\hline Delivery method & Advantages & Limitations \\
\hline $\begin{array}{ll}\text { Intracoronary artery } \\
\text { infusion }\end{array}$ & $\begin{array}{l}\text { Direct infusion } \\
\text { infarct-related } \\
\text { coronary artery } \\
\text { cell engraftment } \\
\text { homogenously at } \\
\text { infarct borders }\end{array}$ & $\begin{array}{l}\text { Not applicable to occluded artery. } \\
\text { Possible micro embolism during } \\
\text { infusion }\end{array}$ \\
$\begin{array}{lll}\text { Surgical } \\
\text { intramyocardial } \\
\text { injection }\end{array}$ & $\begin{array}{l}\text { Smaller number of } \\
\text { cells required direct } \\
\text { inspection }\end{array}$ & $\begin{array}{l}\text { Increased risk of morbidity and } \\
\text { mortality. Potential induction of } \\
\text { arrhythmia. Need for a surgical } \\
\text { approach }\end{array}$ \\
\hline $\begin{array}{l}\text { Transendocardial } \\
\text { injection }\end{array}$ & $\begin{array}{l}\text { Cell delivery in } \\
\text { occluded areas }\end{array}$ & $\begin{array}{l}\text { The risk of myocardial perforation. } \\
\text { Cardiac tamponade and } \\
\text { ventricular arrhythmia }\end{array}$ \\
\hline Transvenous infusion & $\begin{array}{l}\text { Non-invasive } \\
\text { Simple delivery }\end{array}$ & $\begin{array}{l}\text { Possible micro embolism } \\
\text { Low cellular migration and } \\
\text { differentiation. Homing to non- } \\
\text { cardiac organs }\end{array}$ \\
& &
\end{tabular}

Adapted from Ref. (50)

(c) Improved combinatorial approaches

(d) Stem cell priming or pretreatment

(e) Preconditioning

(f) Stem cell Exosomes

(g) Magnetic enhancement techniques

(h) Ultrasound (US) techniques using (a) microbubble destruction and (b) acoustic radiation force

(i) Enhanced homing technique

(j) Stem cell modulation techniques

(k) Mannitol-enhanced delivery

\section{Scaffolds in Stem Cell Delivery}

Scaffolds are biological materials, which act as a template for tissue regeneration and thus guide the growth and formation of the new tissue. The use of scaffolds has been extremely useful in regenerative medicine in that it permits the combination of regenerative cells and angiogenic growth factors as well as allowing control of the cell microenvironment as well increasing cell survival and retention within the ischemic host milieu.

\section{Matrigel}

The encapsulation of cells enhances the formation of multicellular aggregates and also prevents in vivo migration of cells (55). hESCECs encapsulated in Matrigel (enMA-hESC-ECs) have been demonstrated to be superior to hESC-ECs alone in the treatment of limb ischemia as it permits use without direct incorporation enhancing sustained release of various growth factors like VEGF, GM-CSF, IL-6, and IL-8 thus exerting its functional potential through a paracrine effect (29). The encapsulation could also help to overcome the major side effects of transplantation such as teratoma formation and tumors (55).

\section{Cardiogel}

Cardiogel is a biodegradable 3-D cardiac fibroblast-derived extracellular nano-matrix scaffold (56) with a lot of therapeutic potentials for cardiac tissue ischemia. Cardiogel has been shown to support adhesion, differentiation, and proliferation of stem cells (BMSCs) as well as providing increased protection against oxidative stress when compared to Matrigel (57). Cells have been shown to adhere firmly and resist dislodgement even with trypsinization hence preventing flow off to redundant regions of the delivered cells (57).

\section{Hydrogels}

This biomaterial is very attractive as a scaffold because of its similarity to extracellular matrix and under rather mild conditions can be processed. Its delivery is minimally invasive, and its degradation can be designed in a timely way to coincide with the process of angiogenesis (58). Different hydrogel matrices, either natural or synthetic, have been employed as carriers for delivery of cells or growth factors. Naturally occurring molecules that can be utilized include, collagen, fibrin, gelatin, and hyaluronan, alginate, chitosan which are polysaccharides. The synthetic hydrogels include poly (lactic-co-glycolic acid) (PLGA) and polyethylene glycol (PEG).

\section{Collagen}

Less definite matrices, like collagen, were used in the past to provide support for locally injected cells with the restoration of vascular networks (59). These matrices, however, did not provide the needed controlled release of specific growth factors for clinical applications.

However, this downside has seen improvement over the years. For instance, Matsuse et al. (60) designed a combinatorial delivery system using collagen sponge as a matrix for the transplanted neural stem cell (61). Also, it has been combined with gelatin microspheres to enhance the period of vascularization by the gradual release of bFGF. Likewise, to strengthen the use of collagen materials in regeneration, Shi et al. (62) combined three different types of collagen materials in the regeneration of cardiac tissue (demineralized bone matrix collagen scaffolds, collagen gels, and collagen membranes).

\section{Fibrin}

The traditional way of using fibrin for delivery is a physical mixture of the factors with thrombin and fibrinogen during the process of coagulation (63), however, using this method results in an uncontrolled release kinetic of the angiogenic factors VEGF and bFGF, usually within $24 \mathrm{~h}$ (64). New approaches developed to overcome this include covalently linking fibrin to growth factor by factor XIIIa transglutaminase activity during coagulation (65). Another is the use of the engineered variant of VEGF121 ( $\alpha 2$-PII8 -VEGF121), which attaches itself to fibrin during the coagulation process and this prolongs VEGF expression and retention within the fibrin matrix (65). Jeon et al. in their mouse limb ischemic model study, BMMNC and bFGF were transplanted using fibrin as a scaffold. Fibrin was shown to increase density and survival of transplanted cells (32) as the attachment of cells to matrix enhances survival $(66,67)$. Despite the benefits, fibrin has its drawback which is its structural weakness with regards to withstanding the dynamic nature of the in vivo physiological environment, hence the need for the introduction of synthetic biomaterials (PEG, PLGA). 


\section{PEG and PLGA}

PEGylated hydrogels are designed to be biodegradable in response to tissue proteases. The combination of MSCs and ECs with PEG hydrogels resulted in the formation of extensive tubule-like structures and the differentiation of MSCs further enhanced its stability into SMC lineage (68). PEGylated fibrin hydrogels were used in a mouse model of MI to deliver MSCs because of the drawback of fibrin (69), and this demonstrated a 15 -fold cell retention. Also, there was a substantial reduction of apoptosis within and around the scar region and the resulting vascularization led to a significant improvement in the contractile function of the heart.

Poly (lactic-co-glycolic acid) hydrogels also have been used to allow a controlled release of angiogenic factors like VEGF and pre-encapsulated PDGF (70) but without protection in the tissue environment. The PLGA microparticles, an injectable scaffold was designed for the benefit of a prolonged release over months and the choice of polymers with varying release profiles spanning from 1 week to a couple of months controls its gradual degradation into non-toxic products (71). Saif et al., in their study, compared a dual (HGF and VEGF) to a triple (HGF, VEGF, and Ang-1) combination of pro-angiogenic factors in a mouse model of hind limb ischemia. This study was able to demonstrate how Ang-1 helps in the stabilization of newly formed vessels over VEGF. Thus, more vessel formation was induced with the triple combination when compared to the dual therapy (71).

\section{Hyaluronic Acid (HA) and Heparin}

Hyaluronic acid, a glycosaminoglycan with its angiogenic effect dependent on its molecular weights. The high molecular HAs inhibit angiogenesis, while the low HAs enhanced the proliferation and migration of endothelial cells $(72,73)$. HA can be chemically modified to create a hydrogel that is biocompatible with macropores that retain and release angiogenic growth factors in vivo $(74,75)$. On the other hand, heparin incorporation into hydrogel helps to sequester growth factors thereby slowing down their release while still retaining their bioactivity. Heparin stabilizes the growth factors preventing its degradation by ECM proteinases $(76,77)$.

Pike et al. designed a hydrogel of HA and gelatin conjugated with growth factors VEGF and bFGF and demonstrated that incorporation of heparin resulted in an extended release of the growth factors, while the in vivo bioactivity of the growth factors was maintained (78).

\section{StarPEG-Heparin}

StarPEG-heparin is a biohybrid hydrogel which is composed of a star-shaped (multi-armed) poly (ethylene glycol) which is the "starPEG" coupled with heparin (79). This hydrogel can serve as a reservoir and an adaptable release system for heparin-binding factors (VEGF and FGF-2); thus, it is an ideal material for a multifactorial delivery system (80). Likewise, this hydrogel was shown to be suitable for the culture of human umbilical vein endothelial cells, and by adjusting the physiochemical structure of the hydrogel independent of the biomolecular functionalization, the EC behavior such as morphology, proliferation, and survival could be modified (80). Likewise, the attractant for EPCs, the angiogenic protein SDF 1 alpha (SDF-1 $\alpha$ ) have functionalized StarPEGheparin, and by the incorporation of varying concentrations of MMPs, controlled cleavage, and release of varying amounts of SDF- $1 \alpha$ can be achieved (81).

\section{Alginate}

These type of hydrogels have been used to encapsulate angiogenic growth factors VEGF and bFGF (82), hence comparing their angiogenic capacities (83). Neovascularization has been promoted using alginate hydrogels by the localized and sustained delivery of VEGF and bFGF, but a low dose angiogenic signal delivery is essential for the production of a functional vasculature because unregulated hemangioma formation may be a side effect of VEGF and bFGF overdose or vascular leakage that results in edema (58).

Heparinized alginate has been introduced to overcome the initial burst release of growth factors, and the ensuing sustained release of bFGF, for instance, has been shown to treat porcine with MI (84) effectively. More recently, alginate-sulfate-hydrogels (a modified alginate hydrogel) was conjugated to HGF in a rabbit model of hind limb ischemia, which resulted in considerable neovascularization (85).

Further modifications include the RGD (Arg-Gly-Asp) modified alginate gel, which has been shown to improve the attachment and growth of MSC, also facilitated angiogenic growth factor expression. MSCs encapsulated in RGD modified alginate gels promoted repair of the heart muscle with angiogenesis by improved cell survival in an ischemic environment (86).

\section{Poly-L-Lactic Acid (PLLA)}

Poly-L-lactic acid has equally been coupled to RGD to form RGD-g-PLLA synthetic scaffold. These three have been shown to be good for EPC-targeted delivery in vivo as it was proven to promote vessel regeneration in mouse models for dermal wound (87). However, this scaffold was limited by the fact that it appeared to degrade rather slowly. As established, the success of transplanted cells is largely dependent on the adequate and timely degradation of the scaffold which is necessary for the migration of the delivered stem cells (87).

\section{Polyvinylidene Fluoride-Tetrafluoroethylene (PVDF-TrFE) Scaffolds}

The piezoelectric scaffold, electrospun PVDF, and PVDF-TrFE have recently been produced for tissue engineering purposes. This scaffold has proven to be attractive for cardiovascular tissue engineering since the heart is an electroactive tissue (88).

The PVDF-TrFE scaffolds as studied by Pamela et al. revealed that they supported the attachment of and survival of embryonic stem cell CMCs (mES-CM) and endothelial cells (mES-EC) and they both expressed classical endothelial markers such as PECAM1, eNOS, and TM on the scaffolds. The scaffold also supported the contractile action of $\mathrm{mES}-\mathrm{CM}$, while it displayed a higher expression of Notch1 an arterial marker suggesting that it may support arterial specialization. Also, the mES-EC-PVDFTrFE scaffold retained their ability to uptake LDL, a known feature of mature endothelial cells (88). 
However, further studies need to be done to determine the long-term benefits of in vitro cultures using PVDF-TrFE scaffolds, detailed characterization of its piezoelectric activity, as well as its functional integration in vivo (88).

\section{Retrograde Delivery}

In the setting of an MI, blood flow to the distal segment will be cut off and as such infused stem cells will not be able to get to the region of ischemia. In this regard, Wu et al. studied the retrograde delivery of cells via the coronary venous vessel which was initially described by Baklanov et al. This procedure helps to circumvent the blockage to deliver stem cells to the area of ischemia. Unlike the delivery of cells into a coronary arterial vessel which might trigger an ischemic event, $\mathrm{Wu}$ and colleagues demonstrated that the temporary blockage of the coronary sinus did not result in any hemodynamic change and the procedure was well tolerated in the setting of a myocardial injury (50). The advantage of this method is in its ability to administer a lot of cells, low cost, and less invasive when compared to other delivery methods (50).

\section{Improved Combinatorial Approach}

Though the EPCs have a critical role in the formation of blood vessels, the functions of other cells and angiogenic factors cannot be undermined hence the thought of possible combinations. Previous studies have utilized a lot of combinations, but a more recent and classic one is the study by Odent and colleagues, 2015 (89), where they combined the two types of EPC populations. Two distinct types of EPC exist and are described in accordance to how they appear in culture $(90,91)$. These are (1) early outgrowth (EO-EPC), also known as the circulating angiogenic cells (CAC) which appear about 7 days in culture. The proliferative potentials of EO-EPC have been observed to be limited, but with increased secretory activities (89). (2) The late outgrowth (LO-EPC), also known as the endothelial colony-forming cells (ECFC) are circulating EPCs, which are rare and only develop after 2-3 weeks on culture. Both of these cells share common EC markers (CD31/PECAM, KDR/ VEGFR2/Flk-1, CD144/VE-Cadherin) and monocyte markers (CD14, CD45) (92). Concurrent delivery of ECFC and CAC secreting soluble factors has been proven to be of immense benefit for the hind limb ischemia (89). The delivery (i) increases the storage of the cells delivered to the area of ischemia, (ii) pulls in mural cells to facilitate the stability of the new vessels, and (iii) enhances neovascularization and regeneration of muscle tissue. The blood from the umbilical cord has been shown to possess a higher number of ECFC with a significantly greater proliferative potential when compared to cells obtained from the adult peripheral circulation (93), hence the justification for the use of umbilical cord blood for this study. This combination demonstrated a better vascular regeneration, and this was thought to be due to the first endothelial sprouting followed by pericytes \pm SMC recruitment. CAC contributed immensely to vessel maturation by the secretion of angiogenic and vasculogenic factors that promoted survival and proliferation of delivered cells and organized the intercellular junctions between the SMC and ECFC. These factors include VEGF, SDFa (secreted in very high amounts in both normoxic and hypoxic states), PDGF, Ang2, IL-8, ET-1, MCP-1, 10.

Also, Avolio et al. also recently combined human pericytes SVPs (boosts vascularization) with cardiac stem cells (CSC) (promotes cardiomyogenesis) in a mouse MI model (94). This combination additively resulted in a scar size reduction with increased collateralization. The study showed that both cells contributed distinctly rather than cooperatively. SVPs, when compared to CSCs, were shown to have a better incorporation rate and notably, both cell populations were located far from one another in vivo. Particularly, SVPs individually secreted larger amounts of angiogenic factors to include microRNAs (miRs)132. However, coculture suggested some inhibitory effects where these values were significantly reduced in both populations, whereas SDF-1 $\alpha$ was significantly elevated in the coculture (94). Though tissue engineering might be able to harness benefits from both cell populations; this, however, has to be carefully tailored to consider both the existing competitive and cooperative interactions.

Previous combinations include that of EPCs with smooth muscle progenitor cells used in a mice hindlimb ischemia model (95). Here, the combination therapy examined the angiogenic roles and benefits of Ang-1/Tie2 signaling.

Another recent study combined EPCs with MSCs (a source of angiogenic factors and pericyte progenitors) (96). This combination suggests that bone marrow can potentially generate a vast array of chemokines, growth factors, and extracellular matrix molecules derived MSCs (97) with molecular and cellular properties closely similar to that of pericytes $(98,99)$.

\section{Stem Cells Priming/Pretreatment Stem Cell Senescence}

The senescence of stem cells result in the inability of the cells to regenerate injured or ischemic tissues and is thus very detrimental for the life of the organism. The natural aging process and pathologies like diabetes mellitus (DM) contribute to cellular senescence. Cellular senescence has been a challenge for therapeutic tissue regeneration, and a lot of studies have demonstrated that statins, estrogen, high-density lipoprotein, and Insulin-like growth factor-1 can trigger the activity of telomerase (100-103). Also, hypoxia has been shown to inhibit EPC senescence by activating TWIST (104). The priming of stem cells before transplantation is a newly emerging technique in overcoming senescence in stem cells.

When stem cells become senescent, they undergo a couple of changes that include (i) loss of expression of functional markers for ECFC such as, CD34, CXCR4 (which is SDF-1a receptor and though to delay senescence of subpopulations of EPC), VEGFR2, and c-Kit (linked to the recruitment, mobilization and survival of EPCs) (105) and (ii) they express low levels of SMP30 protein, which is a marker of aging and senescence. SMP30 prevent apoptosis in the cells by the inhibition of the caspase cascade.

Fucoidan, the sulfated polysaccharide, is a marine product extracted majorly from diverse species of brown seaweed and brown algae (106). Some functions of Fucoidan have previously been itemized such as in combination with FGF-2 have been 
shown to enhance the angiogenic activities of EPCs (107), increase migration of endothelial cells induced by VEGF165 (108). Lee et al. went further to show the effect of Fucoidan on EPC senescence. Which include (i) restoration of the expression of ECFC functional markers as described above, and this has been shown to be dose-dependent; (ii) prevention of the senescence of ECFC via the phosphorylation of Akt, also with increased and decreased SMP30 protein and p21 levels, respectively. Akt phosphorylation is via the integrin-FAKAkt signaling pathway. Focal adhesion kinase (FAK) promotes survival of cells via PI3K/Akt pathway $(109,110)$. This pathway indirectly modulates the expression of the cell cycle regulators cyclin-dependent kinases ( $\mathrm{Cdk} 2$ and Cdk4). (iii) Acceleration of senescent ECFC's proliferation via phosphorylation of FAK-ERK, ERK signaling regulates various cellular functions, mainly survival and proliferation (111). ERK signaling indirectly controls the expression of p 21 a Cdk inhibitor (cell cycle repressor).

Diabetes can induce a dysfunctional EPC, and microarray studies have confirmed this in a homogenous population of type $1 \mathrm{DM}$ patients (112). Several studies have shown that transplantation of autologous EPCs in the setting of DM foot or the utilization of EPCs from patients with DM yielded very poor neovascularization. Diabetes results in a significant downregulation of a crucial pro-angiogenic glycoprotein Osteopontin $(\mathrm{OPN})$. Vaughan et al. demonstrated that pre-exposure of autologous EPCs to OPN might enhance their efficacy before transplantation. Thus, dysfunctional EPCs can be induced to secrete angiogenic proteins when acted upon in an autocrine manner by OPN (112).

Also, Avolio et al. treated senescent CSC gotten from a decompensated heart with rapamycin and resveratrol and these cells induced cardiac repair when injected into an infarcted mouse heart with the reduction in CMC senescence by reducing the secretion of IL1 $\beta$ (113).

\section{miRNA Pretreated Stem Cells}

microRNAs, a large family of small non-coding RNAs (22-24 nucleotides long), they endogenously regulate gene expression directly or indirectly and play a vital role in cell proliferation, differentiation, and apoptosis (114). The transfection of MSCs with specific miRNAs enhanced their survival and their potential for lineage differentiation thus potentiating MSCs reparative function in ischemia.

Mesenchymal stem cells have been transfected with several miRNAs such as miR-378 (115), MSC Anti-377 (116), miR-126 (117). MSCs transfected with mi-R378 compared to the control, showed a more rapid proliferation, decreased apoptosis, decreased BCL2 levels, upregulated BAX, reduced expression of TNF- $\alpha$, decreased TUSC-2, and formed a higher number of vascular branches. Mi-378 transfection also augmented the expression of VEGF- $\alpha$, PDGF- $\beta$, and TGF- $\beta 1$ (115). However, an in vivo study of MSC-miR-378 affection is yet to be conducted.

miR-377 binds directly to VEGF and negatively regulates its expression (116). Wen et al demonstrated a significant improvement in myocardial angiogenesis when treated with MSCAnti-377, also the degree of fibrosis was observed to be less when compared to MSC-null injected cardiac tissue (116).
Huang et al. demonstrated that MSCs pretreated with miR126 encoded in a lentiviral vector survived for a longer period of time under hypoxic environment (117). MSC-miR-126 efficiently expressed miR-126 for a minimum of 2 weeks at the injected site with no demonstrable adverse effects on cell viability. The overexpression of miR-126 led to the upregulation of VEGF, Notch ligand DII-4, and bFGF in the MSCs. It also improved the survival of MSCs and increased functional angiogenesis in the ischemic heart tissue. However, the study could not explain how the overexpression of miR-126 enhanced the paracrine effects of MSCs.

\section{Preconditioning}

This approach includes (i) electrical stimulation and (ii) ischemic preconditioning both of which has been proven to promote posttransplantation stem cell survival and improved heart function by probably altering exosome contents and functions. It has been proposed that the beneficial effects of either approach occur from induction of cellular stress (118).

Kim et al. showed that CSCs preconditioned with electrical stimulation demonstrated a decreased apoptosis both in vitro and in vivo by upregulating the pro-survival pathways PI3K/AKT and FAK causing the release of connective tissue growth factor (CTGF) (119). miR-378 was shown to regulate the expression of CTGF. CTGF has known effects on tissue repair, fibrosis, scarring, protection against reperfusion injury, ES adhesion and survival. Also, CTGF has been shown to bind to a number of growth factors and mediators that direct a variety of cellular pathways (119). However, their study did not explore the impact of electrical stimulation on exosomes as well as the cytoprotective effects of electrical stimulation.

Ischemic preconditioning is a process where cells are exposed to repeated cycles of anoxia with intermittent re-oxygenation. Kim and colleagues, in a study of ischemic preconditioning, demonstrated an intracellular increase in the levels of miR-210. The expression of this miRNA resulted in the activation of the AKT/ERK1/2 survivals pathways targeting the Caspase-8assoicated protein 2, an initiator of apoptosis (119). A recent study by Feng et al., not only demonstrated the expression and loading of the antiapoptotic miR-22 in exosomes but was able to capture the dynamic intracellular course of exosomes and the extracellular shedding of miRNA-loaded exosomes. miRNA-22 reduced apoptosis in ischemic CMCs by directly targeting methyl binding protein 2, ameliorated fibrosis, and enhanced cardiac function (120).

The window of protection offered by electrical stimulation is shorter when compared to ischemic preconditioning, and this further supports their different molecular signaling pathways (117).

\section{Stem Cell Exosomes}

Stem cells demonstrably secrete paracrine factors not only in naked forms but also membrane bound vesicles such as exosomes among others (121). Exosomes are secreted vesicles, $30-100 \mathrm{~nm}$ in diameter and are also referred to as extracellular vesicles. They are essentially composed of a host of biologically active molecules, such as messenger RNAs (mRNAs), miRs, and 
proteins (122). Exosome formation is initiated from the invagination of the endosomal membrane that results in the formation of intraluminal vesicles or multivesicular bodies (MVBs), which in the process accumulate cytoplasmic molecules such as mRNAs, miRs, and proteins (123). The ILVs/MVBs fuse with the plasma membrane and are released into the extracellular environment by exocytosis as exosomes. MVB formation has been reported to be mediated by the endosomal sorting complexes required for transport (ESCRT) and other ESCRT independent machinery (124). The other molecules involved in the exosome formation are the tetraspanins (CD9, CD63, and CD81) which are expressed on exosomes and can be used as exosome identity markers (121).

Exosomes isolated from different types of stem cells such as MSCs, iPSCs, cardiac progenitor cells, ESCs, and CD34+ have been utilized in the study of cardiac and limb ischemia. In these studies, exosomes were shown to significantly suppress apoptosis (120, 125-127), stimulate angiogenesis $(125,127-131)$, reduce infarct size $(128,132,133)$, and recover cardiac function (125, $127,128,131-133)$. Also, they have been shown to be enriched in miRs such as miR-22 (120), miR-19a (133), miR-133b (134), miR146a (125), miR-294 (131), and sonic hedgehog, a pro-angiogenic factor (135).

Despite the demonstrable angiogenic benefits of exosomes for CMC regeneration after an acute MI, MSC-derived exosomes have also been shown to promote tumorigenesis in vivo by stimulating VEGF in tumor cells (136). Therefore, a technique to specifically deliver the exosomes to target tissues needs to be explored.

\section{Magnetically Targeted Delivery of Stem Cells}

This study involves the use of biocompatible nanoparticles that are magnetically responsive for the targeted transplantation of stem cells so as to facilitate their retention in the region of therapeutic interest. Furthermore, these nanoparticles can be utilized for tracking and monitoring of cells in vivo with the use of magnetic resonance imaging.

\section{Magnetic Nanoparticles}

The superparamagnetic iron oxide nanoparticles are typically made up of a core of magnetite or maghemite which are both naturally ferromagnets, but at specific radii, they become superparamagnets (137). Superparamagnet iron oxide NPs (SPIONs) can broadly be categorized by their size, which is relevant to the field of study as well as their application. These include the very small superparamagnetic iron oxide NPs, less than $10 \mathrm{~nm}$; ultrasmall superparamagnet iron oxide NPs, $10-50 \mathrm{~nm}$; and lastly the SPIONs, 50-180 nm, which are employed in the field of stem cells (137).

\section{Stem Cell Tagging with SPIONs}

Stem cells are tagged with the nanoparticles using any of these methods: (i) passive diffusion, (ii) phagocytosis, and (iii) endocytosis, which can be macropinocytosis, clathrin, or caveolae-mediated endocytosis and other variants that are independent of clathrin or caveolae (138). However, mostly utilized is the endocytosis, in which the cells are incubated for about 12-48 h (139). Below, in Figure 4, is a schematic summary.

\section{Delivery of Stem Cells Tagged with SPIONs}

Several studies have utilized the SPION-tagged stem cells in vascular injury. Kyrtatos and colleagues used CD133+ EPCs, and they targeted these tagged cells using a magnetic device at the site of catheterization in the common carotid artery of a rat hoping to prevent re-obstruction post angioplasty. The engrafted CD133+ tagged cells to the area of injury had 5.4-factor increase about the control. The SPION technique has also been used in heart models to overcome the "Washout" or "displacement" of stem cells during cardiac contraction or coronary blood flow (140). Vandergriff and colleagues, in their study, used Feraheme, coupled with heparin $(\mathrm{H})$ and protamine $(\mathrm{P})$ sulfates forming complexes of FHP (139), and then incubated the cardiospheres with these complexes. The tagged cardiospheres experimented on a rat ischemic heart model with a magnetic field applied. Exposure to the magnet increased the rate of cell retention by three folds about the control. Also, there was no remarkable inflammatory difference (CD68 marker used) about control demonstrating its safety with improvement in cardiac morphology, remodeling, and scar attenuation.

Other areas to be considered in this delivery method include (i) the number of cells (dose), (ii) the magnetic intensities, (iii) duration of the application of the magnet, and (iv) cell size. Cheng, in his study in 2012 (141), in a rat ischemic heart model injected iron microsphere labeled cells derived from cardiospheres into the left anterior coronary artery and a $1.3 \mathrm{~T}$ magnet placed $1 \mathrm{~cm}$ above the heart. The 24 -h cell retention was enhanced by a factor of 5.2-6.4 about control. They also demonstrated that the infusion of $1 \times 10^{5}, 3 \times 10^{5}$, or $5 \times 10^{5}$ cells resulted in no elevation of serum troponin levels, but higher cell number $\left(1 / 2 \times 10^{6}\right)$ raised troponin levels with no improvement in cell retention. This effect was attributed to microvascular obstruction (141).

After that, Shen et al. compared the effect of different magnetic intensities for MSC targeting for myocardial ischemic repair. The left ventricle was injected with SPION-tagged $1 \times 10^{6}$ MSCs with the application of magnetic intensities of $0.15,0.3$, and $0.6 \mathrm{~T}$ (142). This study showed a magnetic dose-dependent increase in cell retention, but at $0.6 \mathrm{~T}$, there was no significant therapeutic outcome as MSC engraftment was confirmed to be low. Microembolism was linked to the therapeutic outcome observed at the too high magnetic strength (142). However, a different study affirmed that the cell dosage $\left(1 \times 10^{6}\right)$ could also result in micro embolism regardless of magnetic intensity (141). So far, $10 \mathrm{~min}$ have been utilized for the magnet application, time. However, this is yet to be fully optimized (141) and also the smaller cells might less likely result in micro embolisms, so embryonic-like $(2-4 \mu \mathrm{m})$ stem cells have to be looked into Ref. (142).

For its application in humans, Cheng and Vandergriff et al. proposed the schematic below in Figure 5.

\section{US in Stem Cell Delivery}

Ultrasound is another novel method of stem cell delivery where acoustic force is used to enhance delivery of stem cells 


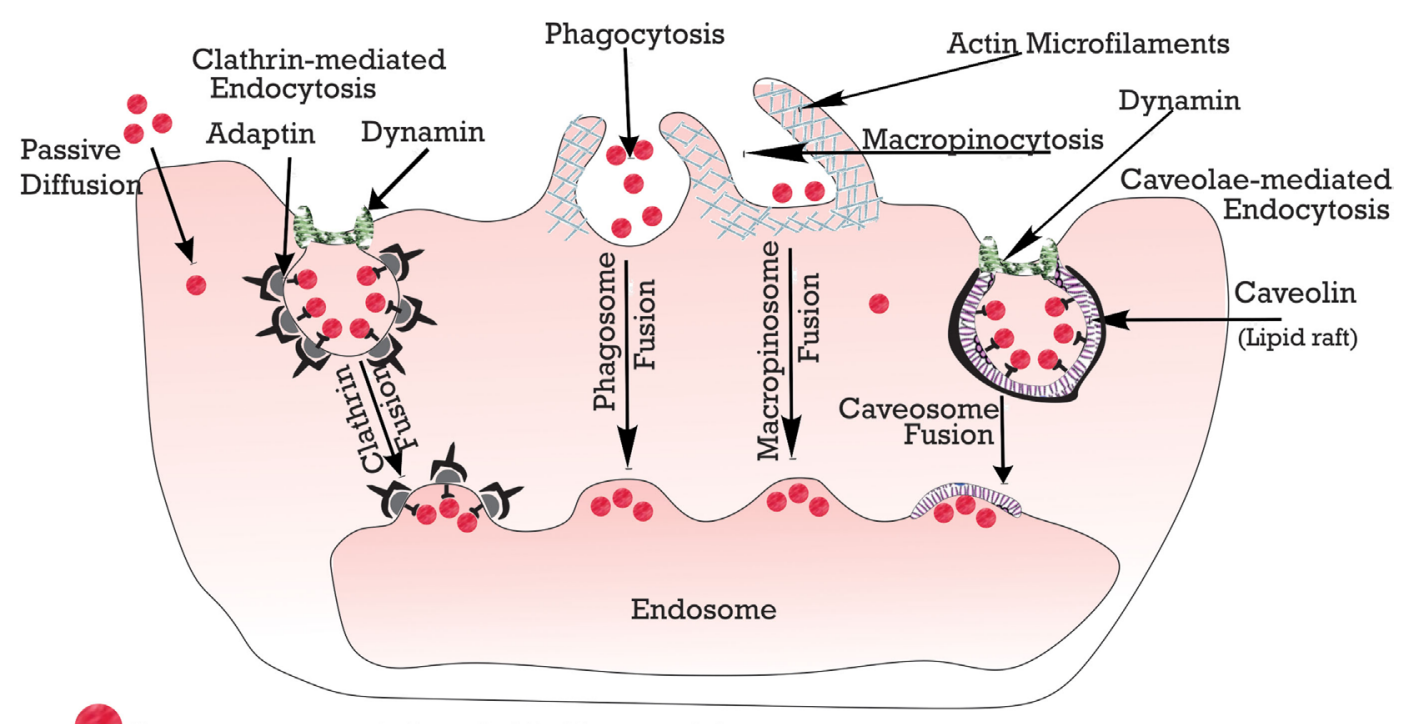

Superparamagnetic Iron Oxide Nanoparticle

FIGURE 4 | Schematic overview of tagging stem cells with SPIONs.

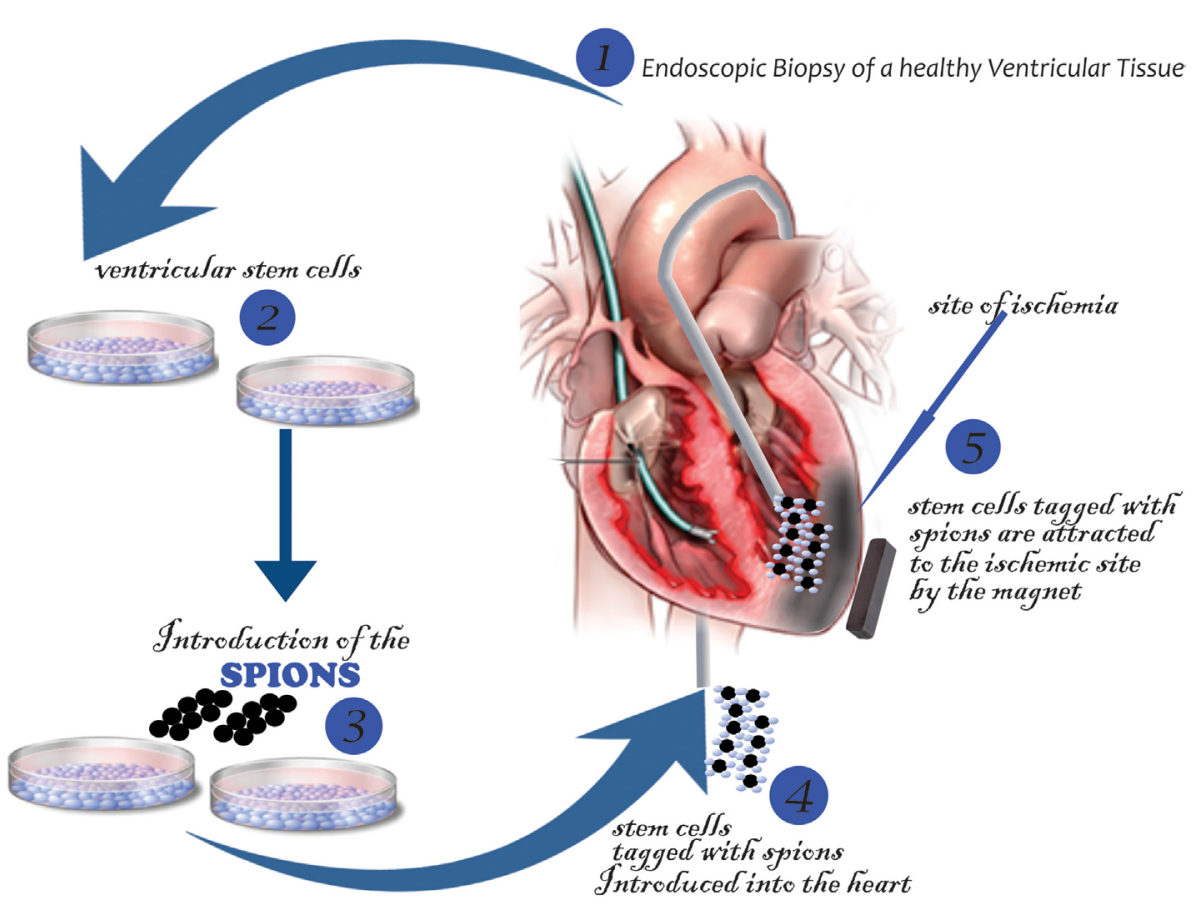

FIGURE 5 | Delivery of stem cells tagged with SPIONs.

to target sites. There are currently two approaches: (i) the US ability to displace cells toward the target site and (ii) the US directed modification of the target site microenvironment. The US delivery systems utilize microbubbles for its function. The first description of the delivery of stem cells using US radiation was by Toma et al. and was based on the intravascular catheter displacement of MSCs coated with gas filled, lipid-shelled microbubbles (143). The schema in Figure 6 demonstrates its possible design in humans.

The attachment of the microbubbles to the surface was catatonically enhanced, and microbubble number of about 7-11 facilitated the greatest adhesion of MSCs (143). However, 


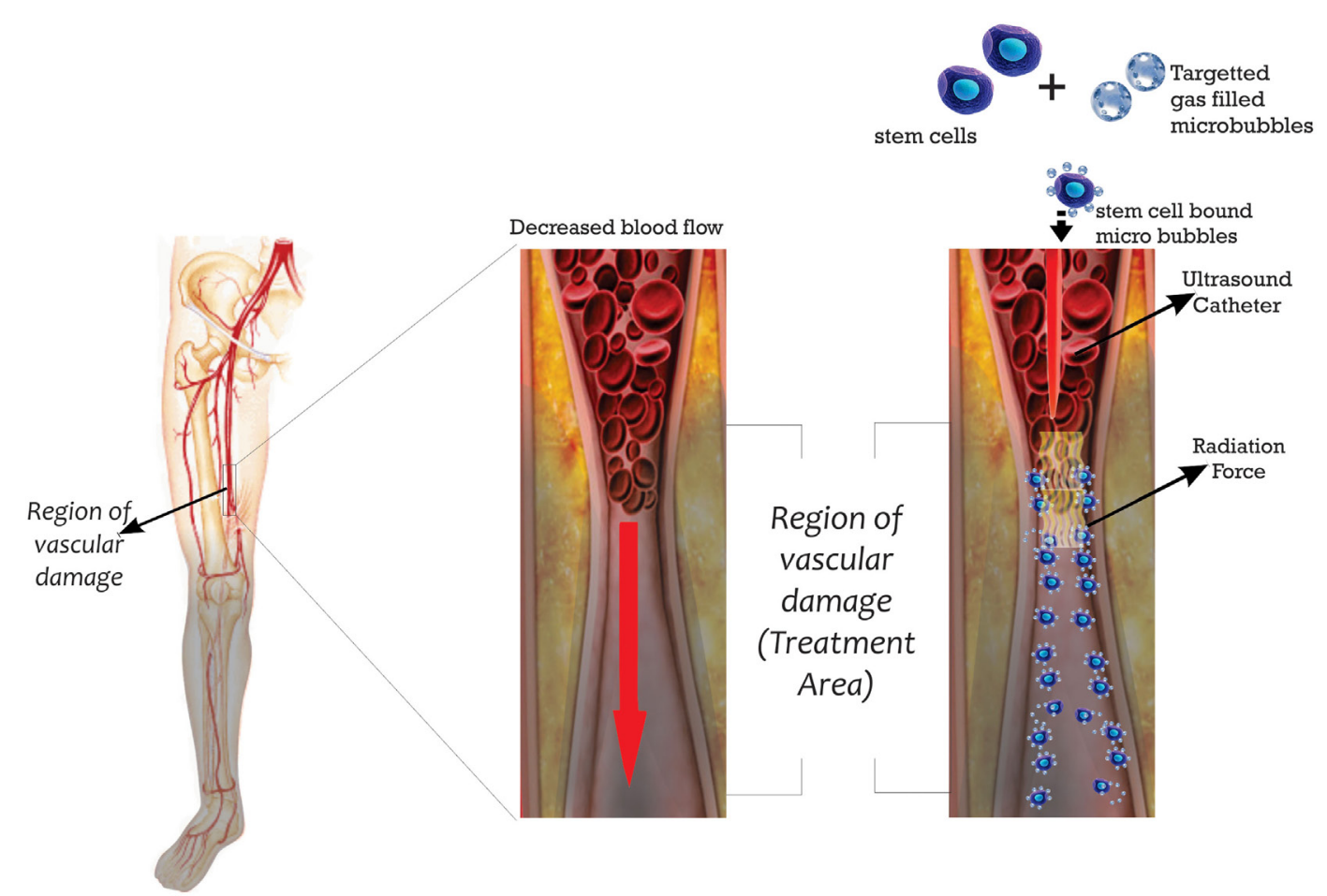

FIGURE 6 | US enhanced delivery of stem cells bound microbubbles.

increasing microbubble coating resulted in a corresponding decrease in adhesion of cells, and this effect was attributed to physical interference by the microbubbles (143). The target site MSC enrichment was outstanding being up to a factor of 150 when compared to the SPIONs loaded EPC which yielded only a target site enrichment of a factor of 6 over control (141). The extended exposure to the microbubbles, however, resulted in a $5 \%$ excess MSC death more than control. In all, the cell type and the catheter used for this delivery will still require further studies.

The other approach is the alteration of the microenvironment of the target site by "US-targeted microbubble destruction" (UTMD). Ling et al. used this system in dog model 1 week after the MI, where a $1 \mathrm{MHz}$ transducer with a $2 \mathrm{~cm}$ diameter was used to irradiate the left ventricular wall after the femoral vein was injected with $2 \mathrm{ml}$ of microbubbles for $10 \mathrm{~min}$ (144). The UTMD can enhance permeability and rupture of the microvasculature (145) and also promote angiogenesis by stimulating the secretion of endogenous angiogenic growth factors $(146,147)$. The irradiated site resulted in some modification of the microenvironment, which stimulated some inflammatory response that was useful for mobilizing stem cells (144). However, excessive infiltration of inflammatory cells may induce apoptosis or necrosis (148). UTMD demonstrably improved angiogenesis, collateral coronary circulation, and myocardial perfusion (144).

The probable mechanism may be that the capillary rupture and the endothelial widening promoted the stem cell attachment to the damaged endothelial layer with cytokine release further enhancing the homing process of the cells (144). The side effects documented for this procedure include necrosis or apoptosis of
CMCs, arrhythmias, extensive destruction of the endothelium, and leakage of micro-vessels.

\section{New Homing Enhancing Technique}

Several studies have reported that transplanted EPCs home to regions of ischemic injury $(62,149)$. However, the precise homing mechanisms are not completely understood; however, playing a central role is the interaction between molecules on the surface of EPCs and upregulated ligands at the site of injury. Recently, Heo et al. (150) showed that homing of transplanted human EPCs and vascular repair was promoted by repeated injections of WKYMVm a synthetic peptide (a chemoattractant for human phagocytes) into ischemic limbs, this subsequently activated formyl peptide receptor 2 (FPR2) on EPCs. EPCs begin to express FPR2 and FPR3 from day 7 to 10 in culture. The binding of WKYMVm to FPR2 induces the proliferating, migrating, and sprouting activities of EPCs (150).

\section{Stem Cell Modulation}

The hunt for the best ways to improve the delivery of stem cells to areas of ischemia appears unending as the fields of immunology, molecular biology, genetic, and proteomics also have their part to contribute. Leading the wave are (i) antibody, (ii) genetic, (iii) selectin, and (iv) peptide-directed approaches (151).

\section{Antibodies}

These involve two strategies: (i) the use of Palmitate protein-G or A to attach antibodies to the surfaces of cells including stem cells and (ii) the use of antibodies that are "bispecific" having affinities 
for the cell to be delivered and the region of interest. However, the use of protein- $G$ is more favored as the production of bispecific antibodies could be challenging and have shown some instability. HSCs have been targeted to an injured cardiac vessel using bispecific antibodies; these were done using either anti-c-kit conjugated to anti-VCAM (152), anti-myosin light chain kinase, or anti-CD45 (153).

\section{Genetic Manipulation}

This is where DNA or RNA is introduced into a cell to aid the expression of ligands on the surface of the cell to enhance homing and attachment to tissue of interest. Increased homing of MSCs transduced with CXCR4 toward an infarcted heart was found to improve cardiac output and angiogenesis within an infarcted heart $(154,155)$. This method though seems lucrative, but the possibility of its translation for clinical use is certainly daunting.

\section{Selectin}

This approach is designed to mimic the natural immunity of the body. Sackstein et al. (156) modified the "selectin-directed cell targeting" pioneered by Xia et al. (157) to modify the surface of MSCs forming HCELL, which is a ligand that binds to E-selectin and L-selectin. Stem cells coated with selectin-binding ligands penetrated through the EC and the layers of the basement membrane to migrate to the area of pathology from the circulation.

\section{Peptide Directed}

Here, stem cells coated with targeting peptides were identified by phage display, the technique was pioneered partly by Kean et al. (151). Tissue or cell ligands can be highly specific, and the cell surfaces targeted with multiple ligands. However, it appears no peptide-targeted therapeutic agent has made it to the market yet about the antibody-based one (158).

\section{Mannitol-Enhanced Delivery}

Adult and neonatal ischemic injury to the brain is quite a clinically significant problem with the paucity of therapeutic interventions. For clinicians at present, the treatment of stroke patients is limited to the use of tPA (159). Stem cell therapy in the brain in small clinical trials has proven to be effective but, however, is limited by their delivery into the injured brain as the brain is protected by a Blood-Brain Barrier (BBB). Surgical delivery though very useful, but it is invasive and is accompanied by its own complications (160). Thus, a minimally invasive approach is more favored. Hence, strategies have been designed to fragment the $\mathrm{BBB}$ for the delivered cells to gain entry into the brain substance (159). Gonzales-Portillo et al. did a study et al. which demonstrated that mannitol a substance that transiently opens the BBB-facilitated delivery of stem cells and trophic factors into the brain (159) thus, stem cell therapy combined with mannitol may enhance therapeutic results in adult stroke patients. The use of stem cells in cerebral ischemia has recorded several successes $(161,162)$, and their combination with mannitol might prove lucrative in the management of stroke patients. However, considering the critical function of the $\mathrm{BBB}$, permeating it might allow harmful or inflammatory chemokines or cytokines to breach the barrier and worsen the pathologic site. Therefore, the use of this technique will put into critical consideration the period of permeation and the size of the leakage for selective passage of stem cells and growth factors.

\section{FUTURE WORK: COMBINED DELIVERY OF MACROPHAGES AND STEM CELLS}

The process of ischemia results in tissue apoptosis and necrosis which triggers the cleaning up process, angiogenesis, and remodeling. Macrophages have been shown to play an enormous function during apoptosis and necrosis, tissue clean up, repair or remodeling, and angiogenesis in any ischemic event. The increased post-MI myocardial rupture and mortality in subjects who had their immune system suppressed with methylprednisolone in early clinical trials confirmed the decisive role of the inflammatory process influenced primarily by macrophages $(163,164)$.

The role of macrophages post-ischemic event is critical as it is considered a key player in the post-ischemic regenerative process. Thus, its therapeutic potentials need to be regarded as strongly not just alone as confirmed by the first administration of polarized macrophages by Jetten et al. (39) but possibly in combination with other stem cells for a better therapeutic effect.

Activation of macrophages usually occurs on day 3 postischemia, and the two main patterns of activation include M1 (classical), activated by LPS or $\gamma$-IFN (interferon), and M2 (alternative), which has two subsets M2a and M2c activated by IL-4 and IL-10, respectively. M1 is pro-inflammatory, while M2 is anti-inflammatory (165). See Table 2 below for the summary of secretions.

Furthermore, macrophage cultures have yielded over 150 secretory proteins secreted by macrophages, and some of these proteins are either pro-angiogenic or angiostatic helping to regulate the angiogenic process tightly. In Table 3 is a few of the key secretory proteins of the macrophage.

A number of macrophages in different injury models such as MI, PAD, stroke, and wound healing have been shown to

TABLE 2 | Markers of classical (M1) and alternative (M2) activation.

\begin{tabular}{ll}
\hline Classical (M1) & Alternative (M2) \\
\hline Pro-inflammatory & Anti-inflammatory \\
Fas ligand high & Arginase I/II \\
Interferon $\gamma$ high & CD 163 \\
Interleukin-1 $\beta$ high & Fas ligand low \\
Interleukin-6 high & Basic fibroblast growth factor (FGF) \\
Interleukin-8 high & Interferon $\gamma$ low \\
Interleukin-10 high & Interleukin-4 receptor I \\
Interleukin-12 high & Interleukin-6 low \\
Interleukin-23 high & Interleukin-10 high \\
Matrix metalloproteinases & Interleukin-12 low \\
Nitric oxide (NO) & Interleukin-23 low \\
Extracellular matrix destruction & Extracellular matrix reconstruction \\
Inducible NO synthase & MS-1-high molecular weight protein \\
Tumor necrosis factor $\alpha$ high & Transforming growth factor $\beta$ \\
& Tumor necrosis factor low \\
& Vascular endothelial growth factor
\end{tabular}

Adapted from Ref. (165). 
correlate positively with angiogenesis (166). Macrophages can influence every step of the angiogenic process such as local ECM modification, EC induction to migrate or proliferate, and vascular growth inhibition, once capillaries have been formed (165).

Macrophages induce angiogenesis by expressing MMPs, which disintegrates the basement membrane and degrades the ECM of the capillary, thus facilitating migration of the endothelial cells. Macrophages initially drill a tunnel in the matrix, which is then colonized by either EPCs or capillary sprouts (165). Several MMPs are synthesized by macrophages such as: MMP-1, -3, -7, $-8,-9$, and -12 . However, MMP-9 appears to be most relevant to post-ischemic remodeling, and this is elaborately expressed during the differentiation of macrophages and overexpressed after an ischemic event (167). Macrophages also release (TIMPs) which functions to inhibit MMPs as well regulating cell growth and signaling (168).
TABLE 3 | A few key secretory proteins of macrophages.

\begin{tabular}{ll}
\hline Cytokines and chemokines & Growth factors \\
\hline$\alpha-2$ macroglobulin & Angiotensinogen \\
ADAMTS-4, $-7,-8,-9$ & Basic FGF \\
Angiotensin converting enzyme & Endothelial cell inhibitory factor \\
Caspases $2,3,8,9$ & Granulocyte colony stimulating \\
Cathepsin B & factor \\
Interferon $\alpha$ & Granulocyte-macrophage colony \\
Interleukin-1 $\alpha$ and $\beta,-6,-8,-10$ & stimulating factor \\
Macrophage inflammatory proteins & Insulin-like Growth Factor 1 \\
MMP-1, $-3,-7,-8,-9,-12$ & Macrophage colony stimulating \\
Monocyte chemotactic protein-1 & factor \\
Plasmin & Monocyte chemotactic protein-1 \\
Plasminogen activator inhibitor 1 & Substance-P \\
Proteases and protease inhibitors & Thrombospondin-1 \\
Tumor necrosis factor $\alpha$ & Transforming growth factors $\alpha$ and $\beta$ \\
& Vascular endothelial growth factor
\end{tabular}

Adapted from Ref. (165).

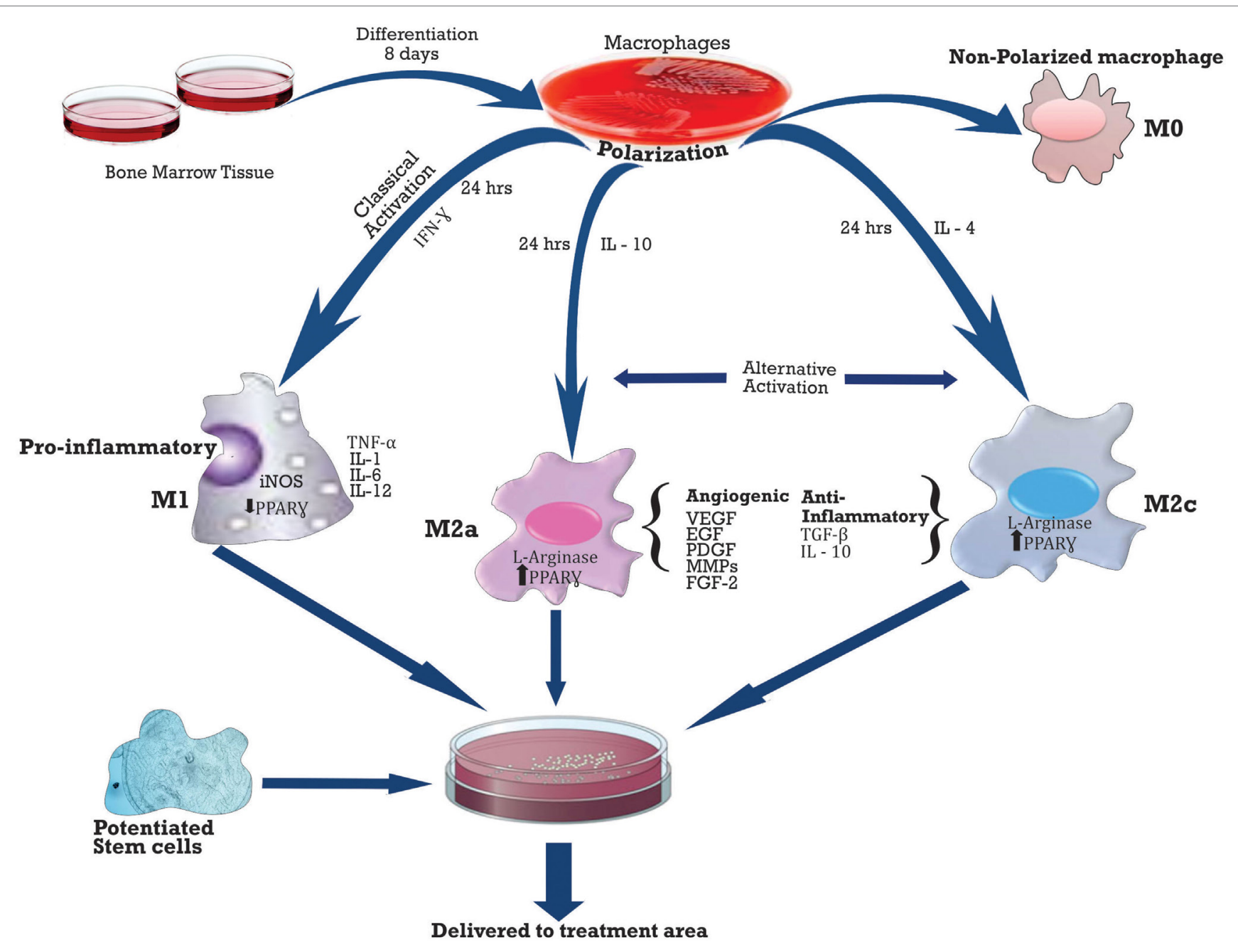

FIGURE 7 | Delivery of Polarized macrophages with potentiated stem cells. 
The fact that tissue ischemia results in reduced blood flow limit the number of monocytes that are available to differentiate into macrophages at the region of ischemia, hence the benefit of the exogenously delivered polarized macrophages. Jetten et al. demonstrated that both M1 and M2 macrophages act in a complementary manner to stimulate arteriogenesis. M1 pro-angiogenic factors, TNF- $\alpha$ and iNOS, and M2-FGF-2 worked in concert with other macrophage-derived growth factors and cytokines during vascular remodeling. Whereas, the non-polarized macrophages did not demonstrate any collateral flow. A possible downside to macrophage delivery might be tissue inflammation; however, there was no documentation of this in the study of Jetten and colleagues. This might be due to the number of the macrophages delivered in the study or the opposing effect of the anti-inflammatory M2 cytokines TGF-B and IL-10 on M1. Hence, further studies might be required to investigate possible tissue inflammation.

Since the goal of delivering stem cells is to achieve the most efficient vascular and tissue regeneration, the tissue reparative role of the macrophage, however, impressive, might not be sufficient. Therefore, studies might be designed to harness the possible synergistic benefits of combining polarized macrophages with potentiated stem cells and delivered in the most efficient way to the region of ischemia. See Figure 7 below.

\section{CONCLUSION}

This study reviewed quite a variety of available new methods of delivering stem cells. A number of these new methods minimized the invasiveness of delivering stem cells to the subject. These

\section{REFERENCES}

1. Norgren L, Hiatt WR, Dormandy JA, Nehler MR, Harris KA, Fowkes FG, et al. Inter-society consensus for the management of peripheral arterial disease (TASC II). J Vasc Surg (2007) 45(Suppl S):S5-67. doi:10.1016/j. jvs.2006.12.037

2. Fowkes FG, Rudan D, Rudan I, Aboyans V, Denenberg JO, McDermott $\mathrm{MM}$, et al. Comparison of global estimates of prevalence and risk factors for peripheral artery disease in 2000 and 2010: a systematic review and analysis. Lancet (2013) 382:1329-40. doi:10.1016/S0140-6736(13)61249-0

3. American Heart Association. Heart Disease and Stroke Statistics. 2007 Update-at-a Glance. (Vol. 2). Dallas, TX: American Heart Association (2007). 37 p.

4. Kikuchi K, Poss KD. Cardiac regenerative capacity and mechanisms. Annu Rev Cell Dev Biol (2012) 28:719-41. doi:10.1146/annurev-cellbio-101011-155739

5. Oh H, Bradfute SB, Gallardo TD, Nakamura T, Gaussin V, Mishina Y, et al. Cardiac progenitor cells from adult myocardium: homing, differentiation, and fusion after infarction. Proc Natl Acad Sci U S A (2003) 100:12313-8. doi:10.1073/pnas. 2132126100

6. Zipes DP, Wellens HJJ. Sudden cardiac death. Circulation (1998) 98:2334-51.

7. Rubart M, Zipes DP. Mechanisms of sudden cardiac death. J Clin Invest (2005) 115:2305-15. doi:10.1172/JCI26381

8. Rumyantsev PP. Interrelations of the proliferation and differentiation processes during cardiac myogenesis and regeneration. Int Rev Cytol (1977) 51:186-273.

9. Soonpaa MH, Rubart M, Field LJ. Challenges measuring cardiomyocyte renewal. Biochim Biophys Acta (2013) 1833:799-803. doi:10.1016/j. bbamcr.2012.10.029 delivery methods resulted in improved retention, survival, and engraftment of these cells and led to remarkable improvements in angiogenesis, collateral vessel formation, improved tissue perfusion, and ultimately salvaged and significantly restored tissue function. Though these studies yielded good success rates in animal models, they however still require extensive studies for translation into humans. The study also proposed possible synergistic benefits that might exist in the efficient delivery of a combination therapy of polarized macrophages with stem cells as this might enhance not only angiogenesis but an efficiently regenerated tissue.

\section{AUTHOR CONTRIBUTIONS}

AF contributed solely to this review with the exception of those listed in the acknowledgement.

\section{ACKNOWLEDGMENTS}

The author wants to acknowledge Professor Paolo Maddedu and Dr. Liang-Fong Wong for their guidance. Oluwaseun Adeniji, Jospeh Elimimian, and David Adeiza Otohinoyi for their assistance. Signed declaration: I declare that this review is entirely my personal work except those acknowledged above.

\section{FUNDING}

Fund for the publishing of this article was provided by Dr. Joshua Yusuf, the President of All Saints University School of Medicine.

10. Adam DJ, Bradbury AW. TASC II document on the management of peripheral arterial disease. Eur J Vasc Endovasc Surg (2007) 33(1):1-2. doi:10.1016/j.ejvs.2006.11.008

11. Ross R. Atherosclerosis - an inflammatory disease. N Engl J Med (1999) 340:115-26

12. Endemann DH, Schiffrin EL. Endothelial dysfunction. J Am Soc Nephrol (2004) 15:1983-92. doi:10.1097/01.ASN.0000132474.50966.DA

13. Carmeliet P. Mechanisms of angiogenesis and arteriogenesis. Nat Med (2000) 6:389-95. doi:10.1038/74651

14. Kubis N, Levy BI. Vasculogenesis and angiogenesis: molecular and cellular controls part 1: growth factors. Interv Neuroradiol (2003) 9:227-37. doi:10.1177/159101990300900301

15. Risau W, Flamme I. Vasculogenesis. Cell Dev Biol (1995) 11:73-91.

16. Kubis N, Levy B. Vasculogenesis and angiogenesis: molecular and cellular controls part 2: growth factors. Interv Neuroradiol (2003) 9:239-48. doi:10.1177/159101990300900302

17. Patan S. Vasculogenesis and angiogenesis as mechanisms of vascular network formation, growth, and remodeling. J Neurooncol (2000) 50:1-15. doi:10.1 023/A:1006493130855

18. Heeko S, Bandykn DF. Therapeutic angiogenesis for critical limb ischemia. Semin Vasc Surg (2014) 27:23-31. doi:10.1053/j.semvascsurg.2014. 10.001

19. Morishita R, Makino H, Aoki M, Hashiya N, Yamasaki K, Azuma J, et al. Phase I/IIa clinical trial of therapeutic angiogenesis using hepatocyte growth factor gene transfer to treat critical limb ischemia. Arterioscler Thromb Vasc Biol (2011) 31:713-20. doi:10.1161/ATVBAHA.110.219550

20. Tomita N, Morishita R, Taniyama Y, Koike H, Aoki M, Shimizu H, et al. Angiogenic property of hepatocyte growth factor is dependent on 
upregulation of essential transcription factor for angiogenesis, ets-1. Circulation (2003) 107:1411-7. doi:10.1161/01.CIR.0000055331.41937.AA

21. Rooney P, Kumar S, Ponting J, Wang M. The role of hyaluronan in tumour neovascularization. Int J Cancer (1995) 60:632-6.

22. Kelly P. Mechanisms of angiogenesis and arteriogenesis. Nat Med (2000) 6:389-95. doi:10.1038/74651

23. Fraisl P. Crosstalk between oxygen-and nitric oxide-dependent signaling pathways in angiogenesis. Exp Cell Res (2013) 319:1331-9. doi:10.1016/j. yexcr.2013.02.010

24. Branco-Price C, Zhang N, Schnelle M, Evans C, Katschinski DM, Liao D, et al. Endothelial cell HIF- 1 alpha and HIF-2alpha differentially regulate metastatic success. Cancer Cell (2012) 21:52-65. doi:10.1016/j.ccr.2011.11.017

25. Fukumura D, Gohongi T, Kadambi A, Izumi Y, Ang J, Yun C-O, et al. Predominant role of endothelial nitric oxide synthase in vascular endothelial growth factor-induced angiogenesis and vascular permeability. Proc Natl Acad Sci U S A (2001) 5(98):2604-9. doi:10.1073/pnas.041359198

26. Collinson DJ, Donnelly R. Therapeutic angiogenesis in peripheral arterial disease: can biotechnology produce an effective collateral circulation? Eur J Vasc Endovasc Surg (2004) 28(1):9-23. doi:10.1016/j.ejvs.2004. 03.021

27. Singh KP, Sharma AM. Critical limb ischemia: current approach and future directions. J Cardiovasc Trans Res (2014) 7:437-45. doi:10.1007/ s12265-014-9562-8

28. Yamahara K, Sone M, Itoh H, Yamashita JK, Yurugi-Kobayashi T, Homma K, et al. Augmentation of neovascularization in hindlimb ischemia by combined transplantation of human embryonic stem cells-derived endothelial and mural cells. PLoS One (2008) 3(2):1-11. doi:10.1371/journal.pone.0001666

29. Cho SW, Moon SH, Lee SH, Kang SW, Kim J, Lim JM, et al. Improvement of postnatal neovascularization by human embryonic stem cell-derived endothelial-like cell transplantation in a mouse model of hindlimb ischemia. Circulation (2007) 116:2409-19. doi:10.1161/ CIRCULATIONAHA.106.687038

30. Wang T, Tang W, Sun S, Ristagno G, Huang Z, Weil MH. Intravenous infusion of bone marrow mesenchymal stem cells improves myocardial function in a rat model of myocardial ischemia. Crit Care Med (2007) 35:11. doi:10.1097/01.CCM.0000285992.99391.7E

31. Iwase T, Nagaya N, Fujii T, Itoh T, Murakami S, Matsumoto $T$, et al. Comparison of angiogenic potency between mesenchymal stem cells and mononuclear cells in a rat model of hindlimb ischemia. Cardiovasc Res (2005) 66:543-51. doi:10.1016/j.cardiores.2005.02.006

32. Jeon O, Kang SW, Lim HW, Choi D, Kim DI, Lee SH, et al. Synergistic effect of sustained delivery of basic fibroblast growth factor and bone marrow mononuclear cell transplantation on angiogenesis in mouse ischemic limbs. Biomaterials (2006) 27:1617-25. doi:10.1016/j.biomaterials.2005. 09.009

33. Ikenaga S, Hamano K, Nishida M, Kobayashi T, Li TS, Kobayashi S, et al. Autologous bone marrow implantation induced angiogenesis and improved deteriorated exercise capacity in a rat ischemic hindlimb model. J Surg Res (2001) 96:277-83. doi:10.1006/jsre.2000.6080

34. Yoon CH, Hur J, Park KW, Kim JH, Lee CS, Oh IY, et al. Synergistic neovascularization by mixed transplantation of early endothelial progenitor cells and late outgrowth endothelial cells: the role of angiogenic cytokines and matrix metalloproteinases. Circulation (2005) 112:1618-27. doi:10.1161/ CIRCULATIONAHA.104.503433

35. Yang C, Zhang ZH, Li ZJ, Yang RC, Qian GQ, Han ZC. Enhancement of neovascularization with cord blood CD133+ cell-derived endothelial progenitor cell transplantation. Thromb Haemost (2004) 91:1202-12. doi:10.1160/TH03-06-0378

36. Kinnaird T, Stabile E, Burnett MS, Shou M, Lee CW, Barr S, et al. Local delivery of marrow-derived stromal cells augments collateral perfusion through paracrine mechanisms. Circulation (2004) 109(12):1543-9. doi:10.1161/01. CIR.0000124062.31102.57

37. Hirose N, Maeda H, Yamamoto M, Hayashi Y, Lee GH, Chen L, et al. The local injection of peritoneal macrophages induces neovascularization in rat ischemic hind limb muscles. Cell Transplant (2008) 17:211-22. doi:10.3727/000000008783906919

38. Jetten N, Donners MMPC, Wagenaar A, Cleutjens JPM, van Rooijen N, de Winther MPJ, et al. Local delivery of polarized macrophages improves reperfusion recovery in a mouse hind limb ischemia model. PLoS One (2013) 8(7):e68811. doi:10.1371/journal.pone.0068811

39. Planat-Benard V, Silvestre JS, Cousin B, Andre M, Nibbelink M, Tamarat $\mathrm{R}$, et al. Plasticity of human adipose lineage cells toward endothelial cells: physiological and therapeutic perspectives. Circulation (2004) 109:656-63. doi:10.1161/01.CIR.0000114522.38265.61

40. Bura A, Planat-Benard V, Bourin P, Silvestre JS, Gross F, Grolleau JL, et al. Phase I trial: the use of autologous cultured adipose-derived stroma/ stem cells to treat patients with nonrevascularizable critical limb ischemia. Cytotherapy (2014) 16:245-57. doi:10.1016/j.jcyt.2013.11.011

41. Madeddu P, Campagnolo P, Cesselli D, Zen AAH, Beltrami AP, Kränkel $\mathrm{N}$, et al. Human adult vena saphena contains perivascular progenitor cells endowed with clonogenic and proangiogenic potential. Circulation (2010) 121:1735-45. doi:10.1161/CIRCULATIONAHA.109.899252

42. Madeddu P, Katare R, Riu F, Mitchell K, Gubernator M, Campagnolo P, et al. Transplantation of human pericyte progenitor cells improves the repair of infarcted heart through activation of an angiogenic program involving micro-RNA-132. Circ Res (2011) 109:894-906. doi:10.1161/ CIRCRESAHA.111.251546

43. Jones M, Varella-Garcia M, Skokan M, Bryce S, Schowinsky J, Peters R, et al. Genetic stability of bone marrow-derived human mesenchymal stromal cells in the quantum system. Cytotherapy (2013) 15:1323-39. doi:10.1016/j. jcyt.2013.05.024

44. Roemeling-van Rhijn M, de Klein A, Douben H, Pan Q, van der Laan LJ, Ijzermans JN, et al. Culture expansion induces non-tumorigenic aneuploidy in adipose tissue-derived mesenchymal stromal cells. Cytotherapy (2013) 15:1352-61. doi:10.1016/j.jcyt.2013.07.004

45. Griffin MD, Ryan AE, Alagesan S, Lohan P, Treacy O, Ritter T. Anti-donor immune responses elicited by allogeneic mesenchymal stem cells: what have we learned so far? Immunol Cell Biol (2013) 91:40-51. doi:10.1038/ icb. 2012.67

46. Drukker M, Katz G, Urbach A, Schuldiner M, Markel G, Itskovitz-Eldor J, et al. Characterization of the expression of MHC proteins in human embryonic stem cells. Proc Natl Acad Sci U S A (2002) 99:9864-9. doi:10.1073/ pnas. 142298299

47. Kinnaird T, Stabile E, Burnett MS, Lee CW, Barr S, Fuchs S, et al. Marrow-derived stromal cells express genes encoding a broad spectrum of arteriogenic cytokines and promote in vitro and in vivo arteriogenesis through paracrine mechanisms. Circ Res (2004) 94:678-85. doi:10.1161/01. RES.0000118601.37875.AC

48. Gnecchi M, He H, Liang OD, Melo LG, Morello F, Mu H, et al. Paracrine action accounts for marked protection of ischemic heart by Akt-modified mesenchymal stem cells. Nat Med (2005) 11:367-8. doi:10.1038/nm0405-367

49. Gnecchi M, Zhang Z, Ni A, Dzau VJ. Paracrine mechanisms in adult stem cell signaling and therapy. Circ Res (2008) 103:1204-19. doi:10.1161/ CIRCRESAHA.108.176826

50. Wu K, Mo X, Lu S, Han Z. Retrograde delivery of stem cells: promising delivery strategy for myocardial regenerative therapy. Clin Transplant (2011) 25:830-3. doi:10.1111/j.1399-0012.2011.01508.x

51. Barbash IM, Chouraqui P, Baron J, Feinberg MS, Etzion S, Tessone A, et al. Systemic delivery of bone marrow-derived mesenchymal stem cells to the infarcted myocardium: feasibility, cell migration, and body distribution. Circulation (2003) 108:863. doi:10.1161/01.CIR.0000084828.50310.6A

52. Yousef $M$, Schannwell CM, Kostering $M$, Zeus T, Brehm M, Strauer BE. The BALANCE Study: clinical benefit and long-term outcome after intracoronary autologous bone marrow cell transplantation in patients with acute myocardial infarction. J Am Coll Cardiol (2009) 53:2262. doi:10.1016/j. jacc.2009.02.051

53. Zhang H, Song P, Tang Y, Zhang XL, Zhao SH, Wei YJ, et al. Injection of bone marrow mesenchymal stem cells in the borderline area of infarcted myocardium: heart status and cell distribution. J Thorac Cardiovasc Surg (2007) 134:1234. doi:10.1016/j.jtcvs.2007.07.019

54. Lee W, Wei H, Lin W, Yeh Y, Hwang S, Wang J, et al. Enhancement of cell retention and functional benefits in myocardial infarction using human amniotic-fluid stem-cell bodies enriched with endogenous ECM. Biomaterials (2011) 32:5558-67. doi:10.1016/j.biomaterials.2011.04.031

55. Moon SH, Kim JS, Park SJ, Lee HJ, Do JT, Chung HM. A system for treating ischemic disease using human embryonic stem cell-derived endothelial cells 
without direct incorporation. Biomaterials (2011) 32:6445-55. doi:10.1016/j. biomaterials.2011.05.026

56. Santhakumar R, Vidyasekar P, Verma RS. Cardiogel: a nano-matrix scaffold with potential application in cardiac regeneration using mesenchymal stem cells. PLoS One (2014) 9(12):e114697. doi:10.1371/journal.pone. 0114697

57. Sreejit P, Verma RS. Cardiogel supports adhesion, proliferation and differentiation of stem cells with increased oxidative stress protection. PE Eur Cells Mat (2011) 21:107-21. doi:10.22203/eCM.v021a09

58. Rufaihah AJ, Seliktar D. Hydrogels for therapeutic cardiovascular angiogenesis. Adv Drug Delivery Rev (2016) 96:31-3. doi:10.1016/j.addr.2015. 07.003

59. Suuronen EJ, Veinot JP, Wong S, Kapila V, Price J, Griffith M, et al. Tissueengineered injectable collagen-based matrices for improved cell delivery and vascularization of ischemic tissue using $\mathrm{CD} 133^{+}$progenitors expanded from the peripheral blood. Circulation (2006) 114(1 Suppl):I138-44. doi:10.1161/ CIRCULATIONAHA.105.001081

60. Matsuse D, Kitada M, Ogura F, Wakao S, Kohama M, Kira JI, et al. Combined transplantation of bone marrow stromal cell-derived neural progenitor cells with a collagen sponge and basic fibroblast growth factor releasing microspheres enhances recovery after cerebral ischemia in rats. Tissue Eng Part A (2011) 17:1993-2004. doi:10.1089/ten.TEA.2010.0585

61. Takamoto T, Hiraoka Y, Tabata Y. Enhanced proliferation and osteogenic differentiation of rat mesenchymal stem cells in collagen sponge reinforced with different poly (ethylene terephthalate) fibers. J Biomater Sci Polym Ed (2007) 18:865. doi:10.1163/156856207781367738

62. Shi C, Li Q, Zhao Y, Chen W, Chen B, Xiao Z, et al. Stem-cell-capturing collagen scaffold promotes cardiac tissue regeneration. Biomaterials (2011) 32:2508-15. doi:10.1016/j.biomaterials.2010.12.026

63. Kipshidze N, Kipiani K, Beridze N, Roubin G, Tsapenko M, Shehzad MZ, et al. Therapeutic angiogenesis for patients with limb ischemia by utilization of fibrin meshwork. Pilot randomized controlled study. Int Angiol (2003) 22:349-55.

64. Shireman PK, Hampton B, Burgess WH, Greisler HP. Modulation of vascular cell growth kinetics by local cytokine delivery from fibrin glue suspensions. J Vasc Surg (1999) 29:852-61.

65. Zisch AH, Schenk U, Schense JC, Sakiyama-Elbert SE, Hubbell JA. Covalently conjugated VEGF-fibrin matrices for endothelialization. J Control Release (2001) 72:101-13. doi:10.1016/S0168-3659(01)00266-8

66. Orlic D, Kajstura J, Chimenti S, Jakoniuk I, Anderson SM, Li B, et al. Bone marrow cells regenerate infarcted myocardium. Nature (2001) 5410:701-5. doi:10.1038/35070587

67. Ryu JH, Kim IK, Cho SW, Cho MC, Hwang KK, Piao H, et al. Implantation of bone marrow mononuclear cells using injectable fibrin matrix enhances neovascularization in infarcted myocardium. Biomaterials (2005) 26:319-26. doi:10.1016/j.biomaterials.2004.02.058

68. Moon JJ, Saik JE, Poché RA, Leslie-Barbick JE, Lee SH, Smith AA, et al. Biomimetic hydrogels with pro-angiogenic properties. Biomaterials (2010) 31:3840-7. doi:10.1016/j.biomaterials.2010.01.104

69. Zhang G, Wang X, Wang Z, Zhang J, Suggs L. A PEGylated fibrin patch for mesenchymal stem cell delivery. Tissue Eng (2006) 12:9-19. doi:10.1089/ ten.2006.12.9

70. Richardson TP, Peters MC, Ennett AB, Mooney DJ. Polymeric system for dual growth factor delivery. Nat Biotechnol (2001) 19:1029-34. doi:10.1038/ nbt1101-1029

71. Saif J, Schwarz TM, Chau DYS, Henstock J, Sami P, Leicht SF, et al. Combination of injectable multiple growth factor-releasing scaffolds and cell therapy as an advanced modality to enhance tissue neovascularization. Arterioscler Thromb Vasc Biol (2010) 30:1897-904. doi:10.1161/ ATVBAHA.110.207928

72. West DC, Kumar S. The effect of hyaluronate and its oligosaccharides on endothelial cell proliferation and monolayer integrity. Exp Cell Res (1989) 185:179-96.

73. Sattar A, Rooney P, Kumar S, Pye D, West DC, Scott I, et al. Application of angiogenic oligosaccharides of hyaluronan increases blood vessel numbers in rat skin. J Invest Dermatol (1994) 103:576-9.

74. Hosack LW, Firpo MA, Scott JA, Prestwich GD, Peattie RA. Microvascular maturity elicited in tissue treated with cytokine-loaded hyaluronan-based hydrogels. Biomaterials (2008) 29:2336-47. doi:10.1016/j. biomaterials.2008.01.033

75. Peattie RA, Rieke ER, Hewett EM, Fisher RJ, Shu XZ, Prestwich GD. Dual growth factor-induced angiogenesis in vivo using hyaluronan hydrogel implants. Biomaterials (2006) 27:1868-75. doi:10.1016/j. biomaterials.2005.09.035

76. Gospodarowicz D, Cheng J. Heparin protects basic and acidic FGF from inactivation. J Cell Physiol (1986) 128:475-84.

77. Folkman J, Shing Y. Control of angiogenesis by heparin and other sulfated polysaccharides. Adv Exp Med Biol (1992) 313:355-64.

78. Pike DB, Cai S, Pomraning KR, Firpo MA, Fisher RJ, Shu XZ, et al. Heparin-regulated release of growth factors in vitro and angiogenic response in vivo to implanted hyaluronan hydrogels containing VEGF and bFGF. Biomaterials (2006) 27:5242-51. doi:10.1016/j.biomaterials.2006. 05.018

79. Chwalek K, Tsurkan MV, Freudenberg U, Werner C. Glycosaminoglycanbased hydrogels to modulate heterocellular communication in in vitro angiogenesis models. Sci Rep (2014) 4:4414. doi:10.1038/srep04414

80. Zieris A, Prokoph S, Levental KR, Welzel PB, Grimmer M, Freudenberg $\mathrm{U}$, et al. FGF-2 and VEGF functionalization of starPEG-heparin hydrogels to modulate biomolecular and physical cues of angiogenesis. Biomaterials (2010) 31(31):7985-94. doi:10.1016/j.biomaterials.2010.07.021

81. Prokoph S, Chavakis E, Levental KR, Zieris A, Freudenberg U, Dimmeler S, et al. Sustained delivery of SDF- $1 \alpha$ from heparin-based hydrogels to attract circulating pro-angiogenic cells. Biomaterials (2012) 33:4792-800. doi:10.1016/j.biomaterials.2012.03.039

82. Downs EC, Robertson NE, Riss TL, Plunkett ML. Calcium alginate beads as a slow release system for delivering angiogenic molecules in vivo and in-vitro. J Cell Physiol (1992) 152:422-9.

83. Lee KY, Peters MC, Mooney DJ. Comparison of vascular endothelial growth factor and basic fibroblast growth factor on angiogenesis in SCID mice. J Control Release (2003) 87:49-56. doi:10.1016/S0168-3659(02) 00349-8

84. Harada K, Grossman W, Friedman M, Edelman ER, Prasad PV, Keighley CS, et al. Basic fibroblast growth factor improves myocardial function in chronically ischemic porcine hearts. J Clin Invest (1994) 94: $623-30$.

85. Ruvinov E, Leor J, Cohen S. The effects of controlled HGF delivery from an affinity binding alginate biomaterial on angiogenesis and blood perfusion in a hindlimb ischemia model. Biomaterials (2010) 31:4573-82. doi:10.1016/j. biomaterials.2010.02.026

86. Yu J, Du KT, Fang Q, Gu Y, Mihardja SS, Sievers RE, et al. The use of human mesenchymal stem cells encapsulated in RGD modified alginate microspheres in the repair of myocardial infarction in the rat. Biomaterials (2010) 31:7012-20. doi:10.1016/j.biomaterials.2010.05.078

87. Kim KL, Han DK, Park K, Song SH, Kim JY, Kim JM, et al. Enhanced dermal wound neovascularization by targeted delivery of endothelial progenitor cells using an RGD-g-PLLA scaffold. Biomaterials (2009) 30:3742-8. doi:10.1016/j.biomaterials.2009.03.053

88. Hitscherich P, Wu S, Gordan R, Xie L-H, Arinzeh T, Lee EJ. The effect of PVDF-TrFE scaffolds on stem cell derived cardiovascular cells. Biotechnol Bioeng (2016) 113:1577-85. doi:10.1002/bit.25918

89. Odent G, Preda MB, Radu E, Rosca AM, Tutuianu R, Mitroi DN, et al. Combinatorial approach for improving the outcome of angiogenic therapy in ischemic tissues. Biomaterials (2015) 60:72-81. doi:10.1016/j. biomaterials.2015.05.002

90. Krenning G, van Luyn MJ, Harmsen MC. Endothelial progenitor cellbased neovascularization: implications for therapy. Trends Mol Med (2009) 15(4):180-9. doi:10.1016/j.molmed.2009.02.001

91. Sieveking DP, Buckle A, Celermajer DS, Ng MK. Strikingly different angiogenic properties of endothelial progenitor cell subpopulations: insights from a novel human angiogenesis assay. J Am Coll Cardiol (2008) 51(6):660-8. doi:10.1016/j.jacc.2007.09.059

92. Hirschi KK, Ingram DA, Yoder MC. Assessing identity, phenotype, and fate of endothelial progenitor cells. Arterioscler Thromb Vasc Biol (2008) 28(9):1584-95. doi:10.1161/ATVBAHA.107.155960

93. Ingram DA, Mead LE, Tanaka H, Meade V, Fenoglio A, Mortell K, et al. Identification of a novel hierarchy of endothelial progenitor cells using 
human peripheral and umbilical cord blood. Blood (2004) 104(9):2752-60. doi:10.1182/blood-2004-04-1396

94. Avolio E, Meloni M, Spencer HL, Riu F, Katare R, Mangialardi G, et al. Combined intramyocardial delivery of human pericytes and cardiac stem cells additively improves the healing of mouse infarcted hearts through stimulation of vascular and muscular repair. Circ Res (2015) 116:e81-94. doi:10.1161/CIRCRESAHA.115.306146

95. Foubert P, Matrone G, Souttou B, Leré-Déan C, Barateau V, Plouët J, et al. Coadministration of endothelial and smooth muscle progenitor cells enhances the efficiency of proangiogenic cell-based therapy. Circ Res (2008) 103:751-60. doi:10.1161/CIRCRESAHA.108.175083

96. Lasala GP, Silva JA, Gardner PA, Minguell JJ. Combination stem cell therapy for the treatment of severe limb ischemia: safety and efficacy analysis. Angiology (2010) 61(6):551-6. doi:10.1177/0003319710364213

97. Minguell JJ, Erices A, Conget P. Mesenchymal stem cells. Exp Biol Med (2001) 226(6):507-20.

98. Crisan M, Deasy B, Gavina M, Zheng B, Huard J, Lazzari L, et al. Purification and long-term culture of multipotent progenitor cells affiliated with the walls of human blood vessels: myoendothelial cells and pericytes. Methods Cell Biol (2008) 86(1):295-309. doi:10.1016/S0091-679X(08) 00013-7

99. Covas DT, Panepucci RA, Fontes AM, Silva WA Jr, Orellana MD, Freitas MC, et al. Multipotent mesenchymal stromal cells obtained from diverse human tissues share functional properties and gene-expression profile with CD146p perivascular cells and fibroblasts. Exp Hematol (2008) 36(5):642-54. doi:10.1016/j.exphem.2007.12.015

100. Landmesser U, Engberding N, Bahlmann FH, Schaefer A, Wiencke A, Heineke A, et al. Statin-induced improvement of endothelial progenitor cell mobilization, myocardial neovascularization, left ventricular function, and survival after experimental myocardial infarction requires endothelial nitric oxide synthase. Circulation (2004) 110:1933-9. doi:10.1161/01. CIR.0000143232.67642.7A

101. Urata Y, Ihara Y, Murata H, Goto S, Koji T, Yodoi J, et al. 17Betaestradiol protects against oxidative stress-induced cell death through the glutathione/ glutaredoxin-dependent redox regulation of Akt in myocardiac H9c2 cells. J Biol Chem (2006) 281:13092-102. doi:10.1074/jbc.M601984200

102. Sumi M, Sata M, Miura S, Rye KA, Toya N, Kanaoka Y, et al. Reconstituted high-density lipoprotein stimulates differentiation of endothelial progenitor cells and enhances ischemia-induced angiogenesis. Arterioscler Thromb Vasc Biol (2007) 27:813-8. doi:10.1161/01.ATV.0000259299.38843.64

103. Thum T, Hoeber S, Froese S, Klink I, Stichtenoth DO, Galuppo P, et al. Agedependent impairment of endothelial progenitor cells is corrected by growth hormone-mediated increase of insulin-like growth-factor-1. Circ Res (2007) 100:434-43. doi:10.1161/01.RES.0000257912.78915.af

104. Lee SH, Lee JH, Yoo SY, Hur J, Kim HS, Kwon SM. Hypoxia inhibits cellular senescence to restore the therapeutic potential of old human endothelial progenitor cells via the hypoxia-inducible factor-1alpha-TWIST-p21 axis. Arterioscler Thromb Vasc Biol (2013) 33:2407-14. doi:10.1161/ ATVBAHA.113.301931

105. Kim MH, Zhang HZ, Kim SW. Combined growth factors enhanced angiogenic potential of cord blood-derived mononuclear cells transplanted to ischemic limbs. J Mol Cell Cardiol (2011) 51:702-12. doi:10.1016/j. yjmcc.2011.07.006

106. Lee JH, Lee SH, Choi SH, Asahara T, Kwon SM. The sulfated polysaccharide fucoidan rescues senescence of endothelial colony-forming cells for ischemic repair. Stem Cells (2015) 33:1939-51. doi:10.1002/stem.1973

107. Zemani F, Benisvy D, Galy-Fauroux I, Lokajczyk A, Colliec-Jouault S, Uzan $\mathrm{G}$, et al. Low-molecular-weight fucoidan enhances the proangiogenic phenotype of endothelial progenitor cells. Biochem Pharmacol (2005) 70:1167-75. doi:10.1016/j.bcp.2005.07.014

108. Lake AC, Vassy R, Di Benedetto M, Lavigne D, Le Visage C, Perret GY, et al. Low molecular weight fucoidan increases VEGF165-induced endothelial cell migration by enhancing VEGF165 binding to VEGFR-2 and NRP1. J Biol Chem (2006) 281:37844-52. doi:10.1074/jbc.M600686200

109. Frisch SM, Vuori K, Ruoslahti E, Chan-Hui PY. Control of adhesiondependent cell survival by focal adhesion kinase. J Cell Biol (1996) 134: $793-9$.
110. Khwaja A, Rodriguez-Viciana P, Wennström S, Warne PH, Downward J. Matrix adhesion and Ras transformation both activate a phosphoinositide 3-OH kinase and protein kinase B/Akt cellular survival pathway. EMBO J (1997) 16:2783-93.

111. Shaul YD, Seger R. The MEK/ERK cascade: from signaling specificity to diverse functions. Biochim Biophys Acta (2007) 1773:1213-26. doi:10.1016/j. bbamcr.2006.10.005

112. Vaughan EE, Liew A, Mashayekhi K, Dockery P, McDermott J, Kealy B, et al. Pretreatment of endothelial progenitor cells with osteopontin enhances cell therapy for peripheral vascular disease. Cell Transpl (2012) 21:1095-107. doi $: 10.3727 / 096368911$ X623880

113. Avolio E, Gianfranceschi G, Cesselli D, Caragnano A, Athanasakis E, Katare R, et al. Ex vivo molecular rejuvenation improves the therapeutic activity of senescent human cardiac Stem cells in a mouse model of myocardial infarction. Stem Cells (2014) 32:2373-85. doi:10.1002/stem.1728

114. Bartel DP. microRNAs: target recognition and regulatory functions. Cell (2009) 136:215-33. doi:10.1016/j.cell.2009.01.002

115. Xing Y, Hou J, Guo T, Zheng S, Zhou C, Huang H, et al. microRNA-378 promotes mesenchymal stem cell survival and vascularization under hypoxic-ischemic conditions in vitro. Stem Cell Res Ther (2014) 5:130. doi:10.1186/scrt520

116. Wen Z, Huang W, Feng Y, Cai W, Wang Y, Wang X, et al. microRNA-377 regulates mesenchymal stem cell-induced angiogenesis in ischemic hearts by targeting VEGF. PLoS One (2014) 9(9):e104666. doi:10.1371/journal. pone. 0104666

117. Huang F, Zhu X, Hu X-Q, Fang Z-F, Tang L, Lu X-L, et al. Mesenchymal stem cells modified with miR-126 release angiogenic factors and activate Notch ligand Delta-like 4, enhancing ischemic angiogenesis and cell survival. Int J Mol Med (2013) 31:484-92. doi:10.3892/ijmm.2012.1200

118. Campbell CR, Berman AE, Weintraub NL, Tang YL. Electrical stimulation to optimize cardioprotective exosome from cardiac stem cells. Tang Med Hypotheses (2016) 88:6-9. doi:10.1016/j.mehy.2015.12.022

119. Kim HW, Haider HK, Jiang S, Ashraf M. Ischemic preconditioning augments survival of stem cells via miR-210 expression by targeting caspase-8-associated protein 2. J Biol Chem (2009) 284(48):33161-8. doi:10.1074/jbc M109.020925

120. Feng $\mathrm{Y}$, Huang $\mathrm{W}$, Wani $\mathrm{M}, \mathrm{Yu} \mathrm{X}$, Ashraf M. Ischemic preconditioning potentiates the protective effect of stem cells through secretion of exosomes by targeting Mecp2 via miR-22. PLoS One (2014) 9:e88685. doi:10.1371/ journal.pone.0088685

121. Suzuki E, Fujita D, Takahashi M, Oba S, Nishimatsu H. Stem cell-derived exosomes as a therapeutic tool for cardiovascular disease. World J Stem Cells (2016) 8(9):297-305. doi:10.4252/wjsc.v8.i9.297

122. Ailawadi S, Wang X, Gu H, Fan GC. Pathologic function and therapeutic potential of exosomes in cardiovascular disease. Biochim Biophys Acta (2015) 1852:1-11. doi:10.1016/j.bbadis.2014.10.008

123. Keerthikumar S, Chisanga D, Ariyaratne D, Al Saffar H, Anand S, Zhao K, et al. ExoCarta: a web-based compendium of exosomal cargo. J Mol Biol (2016) 428:688-92. doi:10.1016/j.jmb.2015.09.019

124. Kowal J, Tkach M, Théry C. Biogenesis and secretion of exosomes. Curr Opin Cell Biol (2014) 29:116-25. doi:10.1016/j.ceb.2014.05.004

125. Ibrahim AG, Cheng K, Marbán E. Exosomes as critical agents of cardiac regeneration triggered by cell therapy. Stem Cell Reports (2014) 2:606-19. doi:10.1016/j.stemcr.2014.04.006

126. Chen L, Wang Y, Pan Y, Zhang L, Shen C, Qin G, et al. Cardiac progenitor-derived exosomes protect ischemic myocardium from acute ischemia/ reperfusion injury. Biochem Biophys Res Commun (2013) 431:566-71. doi:10.1016/j.bbrc.2013.01.015

127. Barile L, Lionetti V, Cervio E, Matteucci M, Gherghiceanu M, Popescu LM, et al. Extracellular vesicles from human cardiac progenitor cells inhibit cardiomyocyte apoptosis and improve cardiac function after myocardial infarction. Cardiovasc Res (2014) 103:530-41. doi:10.1093/cvr/ cvul67

128. Bian S, Zhang L, Duan L, Wang X, Min Y, Yu H. Extracellular vesicles derived from human bone marrow mesenchymal stem cells promote angiogenesis in a rat myocardial infarction model. J Mol Med (2014) 92:387-97. doi:10.1007/ s00109-013-1110-5 
129. Xin H, Li Y, Cui Y, Yang JJ, Zhang ZG, Chopp M. Systemic administration of exosomes released from mesenchymal stromal cells promote functional recovery and neurovascular plasticity after stroke in rats. J Cereb Blood Flow Metab (2013) 33:1711-5. doi:10.1038/jcbfm.2013.152

130. Sahoo S, Klychko E, Thorne T, Misener S, Schultz KM, Millay M, et al. Exosomes from human $\mathrm{CD} 34(+)$ stem cells mediate their proangiogenic paracrine activity. Circ Res (2011) 109:724-8. doi:10.1161/ CIRCRESAHA.111.253286

131. Khan M, Nickoloff E, Abramova T, Johnson J, Verma SK, Krishnamurthy $\mathrm{P}$, et al. Embryonic stem cell-derived exosomes promote endogenous repair mechanisms and enhance cardiac function following myocardial infarction. Circ Res (2015) 117:52-64. doi:10.1161/CIRCRESAHA.117. 305990

132. Arslan F, Lai RC, Smeets MB, Akeroyd L, Choo A, Aguor EN, et al. Mesenchymal stem cell-derived exosomes increase ATP levels, decrease oxidative stress and activate PI3K/Akt pathway to enhance myocardial viability and prevent adverse remodeling after myocardial ischemia/reperfusion injury. Stem Cell Res (2013) 10:301-12. doi:10.1016/j.scr.2013.01.002

133. Yu B, Kim HW, Gong M, Wang J, Millard RW, Wang Y, et al. Exosomes secreted from GATA-4 overexpressing mesenchymal stem cells serve as a reservoir of anti-apoptotic microRNAs for cardioprotection. Int J Cardiol (2015) 182:349-60. doi:10.1016/j.ijcard.2014.12.043

134. Xin H, Li Y, Liu Z, Wang X, Shang X, Cui Y, et al. miR-133b promotes neural plasticity and functional recovery after treatment of stroke with multipotent mesenchymal stromal cells in rats via transfer of exosome-enriched extracellular particles. Stem Cells (2013) 31:2737-46. doi:10.1002/stem. 1409

135. Mackie AR, Klyachko E, Thorne T, Schultz KM, Millay M, Ito A, et al. Sonic hedgehog-modified human CD34+ cells preserve cardiac function after acute myocardial infarction. Circ Res (2012) 111:312-21. doi:10.1161/ CIRCRESAHA.112.266015

136. Zhu W, Huang L, Li Y, Zhang X, Gu J, Yan Y, et al. Exosomes derived from human bone marrow mesenchymal stem cells promote tumor growth in vivo. Cancer Lett (2012) 315:28-37. doi:10.1016/j.canlet.2011.10.002

137. Cores J, Caranasos TG, Cheng K. Magnetically targeted stem cell delivery for regenerative medicine. J Funct Biomater (2015) 6:526-46. doi:10.3390/ jfb6030526

138. Hillaireau H, Couvreur P. Nanocarriers' entry into the cell: relevance to drug delivery. Cell Mol Life Sci (2009) 66:2873-96. doi:10.1007/s00018-0090053-z

139. Gutova M, Frank JA, D’Apuzzo M, Khankaldyyan V, Gilchrist MM, Annala AJ, et al. Magnetic resonance imaging tracking of ferumoxytol-labeled human neural stem cells: studies leading to clinical use. Stem Cells Transl Med (2013) 2:766-75. doi:10.5966/sctm.2013-0049

140. Vandergriff AC, Hensley TM, Henry ET, Shen D, Anthony S, Zhang J, et al. Magnetic targeting of cardiosphere-derived stem cells with ferumoxytol nanoparticles for treating rats with myocardial infarction. Biomaterials (2014) 35:8528-39. doi:10.1016/j.biomaterials.2014.06.031

141. Cheng K, Malliaras K, Li TS, Sun B, Houde C, Galang G, et al. Magnetic enhancement of cell retention, engraftment, and functional benefit after intracoronary delivery of cardiac-derived stem cells in a rat model of ischemia/reperfusion. Cell Transpl (2012) 21:1121-35. doi:10.3727/09636 $8911 X 627381$

142. Shen Y, Liu X, Huang Z, Pei N, Xu J, Li Z, et al. Comparison of magnetic intensities for mesenchymal stem cell targeting therapy on ischemic myocardial repair: high magnetic intensity improves cell retention but has no additional functional benefit. Cell Transpl (2015) 24:1981-97. doi:10.3727 /096368914X685302

143. Toma C, Fisher A, Wang J, Chen X, Grata M, Leeman J, et al. Vascular endoluminal delivery of mesenchymal stem cells using acoustic radiation force. Tissue Eng Part A (2011) 17:9-10. doi:10.1089/ten.TEA.2010.0539

144. Ling ZY, Shu SY, Zhong SG, Luo J, Su L, Liu ZZ, et al. Ultrasound targeted microbubble destruction promotes angiogenesis and heart function by inducing myocardial microenvironment change. Ultrasound Med Biol (2013) 39(11):2001-10. doi:10.1016/j.ultrasmedbio.2013.06.003

145. Wang G, Zhuo Z, Xia H, Zhang Y, He Y, Tan W, et al. Investigation into the impact of diagnostic ultrasound with microbubbles on the capillary permeability of rat hepatomas. Ultrasound Med Biol (2013) 39:628-37. doi:10.1016/j.ultrasmedbio.2012.11.004

146. Song J, Cottler PS, Klibanov AL, Kaul S, Price RJ. Microvascular remodeling and accelerated hyperemia blood flow restoration in arterially occluded skeletal muscle exposed to ultrasonic microbubble destruction. Am J Physiol Heart Circ Physiol (2004) 287:H2754-61. doi:10.1152/ ajpheart.00144.2004

147. Yoshida J, Ohmori K, Takeuchi H, Shinomiya K, Namba T, Kondo I, et al. Treatment of ischemic limbs based on local recruitment of vascular endothelial growth factor-producing inflammatory cells with ultrasonic microbubble destruction. J Am Coll Cardiol (2005) 46:899-905. doi:10.1016/j. jacc.2005.05.052

148. Wagner J, Kean T, Young R, Dennis JE, Caplan AI. Optimizing mesenchymal stem cell-based therapeutics. Curr Opin Biotechnol (2009) 20:531-6. doi:10.1016/j.copbio.2009.08.009

149. Kalka C, Masuda H, Takahashi T, Kalka-Moll WM, Silver M, Kearney $\mathrm{M}$, et al. Transplantation of ex vivo expanded endothelial progenitor cells for therapeutic neovascularization. Proc Natl Acad Sci U S A (2000) 97(7):3422-7. doi:10.1073/pnas.070046397

150. Jang IH, Heo SC, Kwon YW, Choi EJ, Kim JH. Role of formyl peptide receptor 2 in homing of endothelial progenitor cells and therapeutic angiogenesis. Adv Biol Regulation (2015) 57:162-72. doi:10.1016/j.jbior.2014.09.011

151. Kean TJ, Lin P, Caplan AI, Dennis JE. MSCs: delivery routes and engraftment, cell-targeting strategies, and immune modulation. Stem Cells Int (2013) 2013:732742. doi:10.1155/2013/732742

152. Lum LG, Fok H, Sievers R, Abedi M, Quesenberry PJ, Lee RJ. Targeting of Lin-Sca+ hematopoietic stem cells with bispecific antibodies to injured myocardium. Blood Cells Mol Dis (2004) 32(1):82-7. doi:10.1016/j. bcmd.2003.09.019

153. Lee RJ, Fang Q, Davol PA, Gu Y, Sievers RE, Grabert RC, et al. Antibody targeting of stem cells to infarcted myocardium. Stem Cells (2007) 25(3):712-7. doi:10.1634/stemcells.2005-0602

154. Cheng Z, Ou L, Zhou X, Li F, Jia X, Zhang Y, et al. Targeted migration of mesenchymal stem cells modified with CXCR4 gene to infarcted myocardium improves cardiac performance. Mol Ther (2008) 16(3):571-9. doi:10.1038/sj.mt.6300374

155. Zhang D, Fan GC, Zhou X, Zhao T, Pasha Z, Xu M, et al. Over-expression of CXCR4 on mesenchymal stem cells augments myoangiogenesis in the infarcted myocardium. J Mol Cell Cardiol (2008) 44(2):281-92. doi:10.1016/j. yjmcc.2007.11.010

156. Sackstein R, Merzaban JS, Cain DW, Dagia NM, Spencer JA, Lin CP, et al. Ex vivo glycan engineering of CD44 programs human multipotent mesenchymal stromal cell trafficking to bone. Nat Med (2008) 14(2):181-7. doi: $10.1038 / \mathrm{nm} 1703$

157. Xia L, McDaniel JM, Yago T, Doeden A, McEver RP. Surface fucosylation of human cord blood cells augments binding to P-selectin and E-selectin and enhances engraftment in bone marrow. Blood (2004) 104(10):3091-6. doi:10.1182/blood-2004-02-0650

158. Majumdar S, Siahaan TJ. Peptide-mediated targeted drug delivery. Med Res $\operatorname{Rev}(2012)$ 32(3):637-58. doi:10.1002/med.20225

159. Gonzales-Portillo GS, Sanberg PR, Franzblau M, Gonzales-Portillo C, Diamandis T, Staples M, et al. Mannitol-enhanced delivery of stem cells and their growth factors across the blood-brain barrier. Cell Transpl (2014) 23:531-9. doi:10.3727/096368914X678337

160. Borlongan CV, Glover LE, Sanberg PR, Hess DC. Permeating the blood brain barrier and abrogating the inflammation in stroke: implications for stroke therapy. Curr Pharm Des (2012) 18:3670-6. doi:10.2174/138161212802002841

161. Borlongan CV, Hadman M, Sanberg CD, Sanberg PR. Transplantation of cryopreserved human embryonal carcinoma-derived neurons (NT2N cells) promotes functional recovery in ischemic rats. Stroke (2004) 35:2385-9. doi:10.1006/exnr.1997.6730

162. Borlongan CV, Hadman M, Sanberg CD, Sanberg PR. Central nervous system entry of peripherally injected umbilical cord blood cells is not required for neuroprotection in stroke. Stroke (2004) 35:2385-9. doi:10.1161/01. STR.0000141680.49960.d7

163. Mannisi JA, Weisman HF, Bush DE, Dudeck P, Healy B. Steroid administration after myocardial infarction promotes early infarct 
expansion. A study in the rat. J Clin Invest (1987) 79:1431-9. doi:10.1172/ JCI112971

164. Hammerman H, Kloner RA, Hale S, Schoen FJ, Braunwald E. Dose-dependent effects of short-term methylprednisolone on myocardial infarct extent, scar formation, and ventricular function. Circulation (1983) 68:446-52.

165. Lambert JM, Lopez EF, Lindsey ML. Macrophage roles following myocardial infarction. Int J Cardiol (2008) 130:147-58. doi:10.1016/j.ijcard.2008.04.059

166. Manoonkitiwongsa PS, Jackson-Friedman C, McMillan PJ, Schultz RL, Lyden PD. Angiogenesis after stroke is correlated with increased numbers of macrophages: the clean-up hypothesis. J Cereb Blood Flow Metab (2001) 21:1223-31. doi:10.1097/00004647-200110000-00011

167. Lindsey M, Wedin K, Brown MD, Keller C, Evans AJ, Smolen J, et al. Matrixdependent mechanism of neutrophil-mediated release and activation of matrix metalloproteinase 9 in myocardial ischemia/reperfusion. Circulation (2001) 103:2181-7. doi:10.1161/01.CIR.103.17.2181
168. Chirco R, Liu X-W, Jung K-K, Kim H-R. Novel functions of TIMPs in cell signaling. Cancer Metastasis Rev (2006) 25:99-113. doi:10.1007/ s10555-006-7893-x

Conflict of Interest Statement: The author declares that the research was conducted in the absence of any commercial or financial relationships that could be construed as a potential conflict of interest.

Copyright () 2017 Fakoya. This is an open-access article distributed under the terms of the Creative Commons Attribution License (CC BY). The use, distribution or reproduction in other forums is permitted, provided the original author(s) or licensor are credited and that the original publication in this journal is cited, in accordance with accepted academic practice. No use, distribution or reproduction is permitted which does not comply with these terms. 